\title{
Effect of Polypropylene Modification by Impregnation with Oil on Its Wear and Friction Coefficient at Variable Load and Various Friction Rates
}

\author{
Paweł Sędłak, ${ }^{1}$ Beata Białobrzeska, ${ }^{2}$ Tomasz Stawicki, ${ }^{1}$ and Piotr Kostencki ${ }^{1}$ \\ ${ }^{1}$ Department of Agrotechnical Systems Engineering, West Pomeranian University of Technology, Papieza Pawla VI Street 1, \\ 71-459 Szczecin, Poland \\ ${ }^{2}$ Department of Materials Science, Welding and Strength of Materials, Wrocław University of Technology, Smoluchowskiego Street 25 , \\ 50-370 Wrocław, Poland
}

Correspondence should be addressed to Beata Białobrzeska; beata.bialobrzeska@pwr.edu.pl

Received 12 May 2017; Revised 29 September 2017; Accepted 24 October 2017; Published 13 December 2017

Academic Editor: Saad Khan

Copyright (C) 2017 Paweł Sędłak et al. This is an open access article distributed under the Creative Commons Attribution License, which permits unrestricted use, distribution, and reproduction in any medium, provided the original work is properly cited.

\begin{abstract}
Laboratorial two-body wear testing was carried out in order to assess effects of polypropylene modification by impregnating it with oils on friction coefficient and wear in comparison to those parameters of unmodified polypropylene, Teflon, and polyamide during operation under conditions of sliding friction without lubrication. Wear behaviour of the tested specimens was investigated using ASTM G77-98 standard wear test equipment. Recording program made it possible to visualise and record the following parameters: rotational speed and load, linear wear, friction coefficient, temperature of the specimen, and ambient temperature. In addition, wear mechanisms of the analysed materials were determined with use of scanning electron microscopy. In the case of the remaining tested polymers, the most important mechanism of wear was adhesion (PP, PTFE, PA 6.6, and PA MoS 2 ), microcutting (PTFE, PA 6.6, and PA $\mathrm{MoS}_{2}$ ), fatigue wear (PTFE), forming "roll-shaped particles" combined with plastic deformation (PA 6.6 and PA MoS 2 ), and thermal wear (PP). Impregnation of polypropylene with engine oil, gear oil, or RME results in significant reduction of friction coefficient and thus of friction torque, in relation to not only unmodified polypropylene but also the examined polyamide and Teflon.
\end{abstract}

\section{Introduction}

Being a science engaged in the phenomena occurring in friction areas of mating parts, tribology considers difficult phenomena determining friction and wear of engineering materials. The factors decidedly affecting tribological processes in friction nodes include friction type, intensity and resistance, nature and value of applied loads, relative velocity, working temperature, and geometry of the friction node, as well as sliding direction with respect to injection flow of the polymer [1]. Wear processes are also affected by stereometry of the outside surface created in the manufacturing processes. The above-mentioned factors determine nature and intensity of destructive processes occurring in the cooperation areas of friction pairs composed of various materials: metal-metal, metal-nonmetal (e.g., a polymer), and polymer-polymer [2, 3]. A set of all factors influencing a friction node brings about a specific kind of wear and, more precisely, the dominating wear process. Besides the above-mentioned factors, type of wear is also affected by heat dissipation from the friction area, lubricant supply and properties, and mechanism and intensity of removing wear products, as well as shape and dimensions of the wearing surfaces.

Influence of individual factors on friction and wear processes in friction pairs based on traditional constructional materials can be evaluated, among others, thanks to wellrecognised crystalline structure of these materials and to relatively comprehensive set of experimental data and the information coming from practice. However, traditional tribology developed originally for metals cannot be applied in the case of friction pairs containing polymers because of their rapid improvement [4], and so still new research works are required in order to recognise influence of the a.m. factors on friction and wear processes. It is very difficult to indicate the factors that generate the prevailing wear process and to attribute to them the mechanism responsible for 
wear. This results from various physicomechanical features of polymer materials in relation to those of the mating materials that are most often metals and from a significant influence of temperature on their properties. Significant amount of heat generated in friction pairs based on metals and metal alloys is effectively dissipated to the environment thanks to good thermal conductivity of metals combined with heat collection by the lubricating agent. However, in the pairs based on polymers (including polymer-based composites) characterised by thermal conductivity lower than that of metals, generated heat significantly affects their physicomechanical properties [4]. This restricts the possibility of using polymers in sliding friction nodes to those with low linear velocities and low loads [5]. In particular, polymers are used for friction nodes in machines and facilities in that traditional lubrication is difficult or impossible or building a lubrication system is nonviable. At dry friction, bearings made of polymers show features of self-lubricating (maintenance-free) bearings. When working conditions are known, properties of polymers used in sliding nodes are to some extent deliberately formed by selection of a specific chemical composition that determines their structure, as well as mechanical, thermal, and tribological properties $[6,7]$. Frequently, in order to improve mechanical and tribological parameters of polymers, modification of chemical composition is applied. Most often, metals and alloys (tin, lead, copper, bearing alloys, and oxides of some metals) or nonmetallic additives (graphite, soot, molybdenum disulphide, and chalk of other polymers) are used as modifiers. Form of an addition influences the obtained mechanical and tribological effects. The additives can be applied in form of fine particles with various granularity, fibres with various length, mats, or fabrics, creating with the polymer a polymeric composite [8-10].

Another way of modifying physicomechanical features of pure polymers is their impregnation with liquid lubricants. In this process, porous structure of polymers is utilised, which makes it possible to accumulate the lubricant necessary to reduce frictional resistance and wear in the sliding node [11]. In this case, an issue is uniform and durable impregnation of polymer in its entire volume, as well as influence of the lubricant on physicomechanical properties of the polymer. Quantity of lubricant that can be gathered in the polymer volume depends on structure of its macromolecules and on its cross-linking degree (crystallisation). Here, an indication can be absorbability of water, which is one of the parameters determined by manufacturers of polymers. In addition, structure and size of lubricant particles can influence the impregnation process, since they determine mobility of molecules within the polymer structure. Attention should be also paid to easiness of impregnation of polymeric parts with liquid lubricants and wide selection of possible lubricating agents. However, the number of scientific studies concerning impregnation of polymers with various lubricants and their tribological properties is still insufficient.

\section{Purpose of the Research}

The research was aimed at determining influence of polypropylene modification by impregnation with oils on its friction coefficient and wear in comparison to these properties of unmodified polypropylene, Teflon, and polyamide during their operation at sliding friction without lubrication.

Good properties of polypropylene obtained by impregnation with oils indicate a possibility to use this inexpensive material in maintenance-free sliding nodes.

\section{Materials and Methods}

Specimens of polypropylene (PP) were made of a rod dia. $10.5 \mathrm{~mm}$. Specimens of Teflon (PTFE) and polyamide (PA 6.6 and PA $\mathrm{MoS}_{2}$ ) were made of rods dia. $10 \mathrm{~mm}$. The rods were mechanically cut to $19 \mathrm{~mm}$ long pieces and then shortened to $17 \mathrm{~mm}$ and their edges were chamfered. After thorough cleaning with extraction naphtha and technical acetone, the specimens were weighed on laboratory scales WPS510/C/1 to $\pm 0.001 \mathrm{~g}$ and their diameters were measured with a workshop minimeter to $\pm 0.001 \mathrm{~mm}$.

The polypropylene specimens were modified by impregnation with vegetable oil, that is, rapeseed oil methyl ester (RME), and with two mineral oils, that is, gear oil Hipol GL-4 80W/90 and engine oil HD Diesel Formula 15W/40. Polypropylene specimens were impregnated by submerging in the a.m. oils heated up to $105^{\circ} \mathrm{C}$ and holding for 24 hours. Impregnated specimens were then thoroughly cleaned, measured, and weighed. After the next $24 \mathrm{~h}$, measurements of mass and dimensions were repeated in order to verify whether quantity of the absorbed oil did not change and geometry of the specimens was stable. Depending on the applied oil, various impregnation degrees were obtained (measured by relations of masses after and before impregnation): $15-17 \%$ for RME, $7-9 \%$ for gear oil, and $9-11 \%$ for engine oil. Increments of diameters of the specimens were $0.05-0.08 \mathrm{~mm}(0.62 \%$ in average) for RME, $0.03-0.05 \mathrm{~mm}$ $(0.4 \%$ in average) for gear oil, and $0.04-0.06 \mathrm{~mm}(0.5 \%$ in average) for engine oil.

A counterspecimen for all the examined polymers was a ring dia. $35 \mathrm{~mm}$ and $8 \mathrm{~mm}$ wide, made of bearing steel $Ł H 15$ acc. to PN-H-84041:1974 with the following chemical composition: $0.95-1.1 \% \mathrm{C}, 0.25-0.45 \% \mathrm{Mn}, 1.3-1.65 \% \mathrm{Cr}$, $0.15-0.35 \% \mathrm{Si}, 0.025 \% \mathrm{P}_{\max }, 0.025 \% \mathrm{~S}_{\max }, 0.3 \% \mathrm{Ni}_{\max }$, and $0.3 \% \mathrm{Cu}_{\max }$, which is equivalent to steel $100 \mathrm{Cr} 6$ acc. to EN ISO 683-17:2015-01. The counterspecimen was hardened and tempered to $48 \mathrm{HRC}$ and its surface was subjected to finishing grinding $\left(R_{a}=0.19 \mu \mathrm{m}\right)$.

Individual polymers were examined at linear velocities of $0.13,0.26,0.44$, and $0.62 \mathrm{~m} \cdot \mathrm{s}^{-1}$. The velocities were selected on the grounds of preliminary examinations that showed clear reduction of friction torque at the velocities over $0.62 \mathrm{~m} \cdot \mathrm{s}^{-1}$ due to excessive increase of the polymer temperature, as was also found in [12]. In the examinations, force acting on the friction node increased at constant rate from 0 to $1030 \mathrm{~N}$ and the test time was $480 \mathrm{~s}$. With these assumptions, load growth rate was $2.16 \mathrm{~N} \cdot \mathrm{s}^{-1}$ and friction distances were $62.4,124.8$, 211.2 , and $297.6 \mathrm{~m}$, respectively, for the accepted working velocities. For some material pairs, the assumed maximum force loading the friction node $(1030 \mathrm{~N})$ could not be reached. In these cases, friction torque reached the accepted maximum 


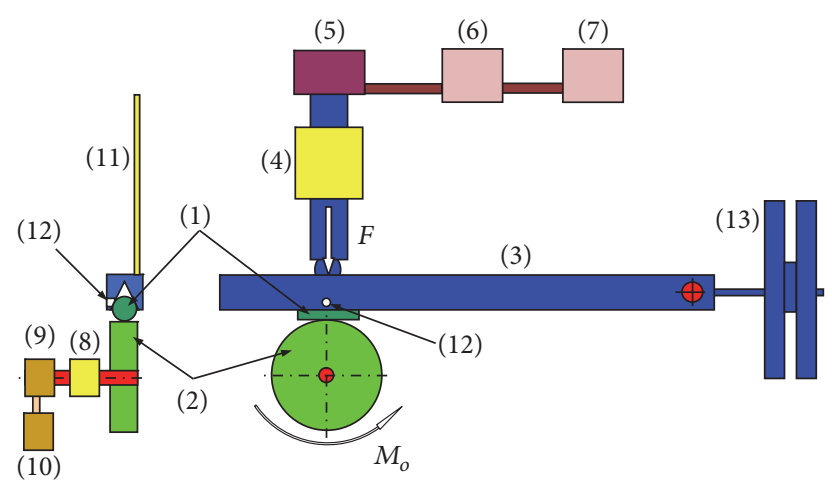

FIGURE 1: Layout of the tribometer used in the tests: (1) specimen, (2) counterspecimen, (3) specimen holder, (4) force sensor, (5) pneumatic cylinder, (6) pneumatic transducer and pressure regulator, (7) compressor, (8) torque meter, (9) electric motor, (10) frequency converter, (11) movement sensor, (12) thermocouple for temperature measurements of the specimen, and (13) counterweight.

permissible value of $350 \mathrm{Ncm}$ at lower load values, and the test station was automatically stopped to avoid its possible failure.

For each material mating and working velocity of the tribological pair, measurements were made in 7 series.

Friction torque between the specimen and the counterspecimen was measured with use of a tribometer designed and manufactured in the Department of Agrotechnical Systems Engineering of West Pomeranian University of Technology, Szczecin [13]. Structure of the tribometer is shown in Figure 1 . The test station was composed of a frequency converter FREQVAR 3000 (10) controlling the electric motor (9), connected via a torque meter (8) (operating ranges $500 \mathrm{Ncm}$ and $3000 \mathrm{rpm}$, accuracy class $0.2 \%$ ) to the counterspecimen (2) creating the examined tribological pair with the specimen (1). Load was applied by a pneumatic cylinder FMP AgrometMogilno (5) cooperating with a compressor (7), a pneumatic transducer A201-A $101 \mathrm{D} 2$, and a pressure regulator AW 300003 (6). Load of the friction pair was controlled by a force sensor (4) (operating range $2 \mathrm{kN}$, reading error $0.1 \%$ ) located between the cylinder and the specimen holder (3). Displacement of the specimen with respect to the counterspecimen was measured by an induction movement sensor LVDT5 (11) (reading error $0.015 \mathrm{~mm}$ ). The tribometer was equipped with a thermocouple TP-202 type $\mathrm{K}(12)$ (reading error $0.1^{\circ} \mathrm{C}$ ). For technical reasons, the thermocouple was located ca. $3 \mathrm{~mm}$ from the friction area (along with the specimen wear, the temperature measurement point came nearer to the friction area). This made it possible to measure general temperature of the specimen and not temperature at the contact point between the specimen and the counterspecimen.

Each time, the test station was prepared and the tests were started according to the guidelines in ASTM G77. The counterspecimen was cleaned with use of waterproof abrasive paper number 600 and then degreased together with the specimen. Next, specimens were once more weighed and fastened in the tribometer holder and the test run was started. Each run commenced from preliminary grinding-in the frictional parts at the set rotational speed and constant load
103 N. During grinding-in, the following phases occurred: accelerating the tribometer to the set rotational speed for $21 \mathrm{~s}$, increasing the load from 0 to $103 \mathrm{~N}$ for $10 \mathrm{~s}$, maintaining the constant rotational speed at $103 \mathrm{~N}$ for $120 \mathrm{~s}$, decreasing the load from $103 \mathrm{~N}$ to 0 for $5 \mathrm{~s}$, and maintaining the constant rotational speed for another $5 \mathrm{~s}$. The last phase of this run was aimed at determining linear wear of the specimen. As a result of grinding-in, all components of the tribological system were properly mutually arranged, and surfaces of the specimen and the counterspecimen were matched. After grinding-in, the actual test run commenced without stopping the counterspecimen.

Operation of the tribometer was controlled by the interface MW- 5 cooperating with the software STEDIT 101 installed in a PC. By means of this system, load of the friction pair with its planned increase rate, rotational speed, and rotational direction of the counterspecimen were set in a controlled way. The recording program permitted rotational speed of the counterspecimen, load, linear wear of the specimen, friction torque between the specimen and the counterspecimen, and temperature of the specimen to be recorded. After a completed test run, the specimen was again weighed in order to determine its mass wear.

On the grounds of averaged actual values of friction torque in the examined tribological pairs, actual values of friction coefficient between the specimen and the counterspecimen were calculated from the following formula:

$$
\mu=\frac{M_{t}}{F \cdot r_{1}},
$$

where $\mu$ is actual value of friction coefficient, $M_{t}$ is actual value of friction torque, $\mathrm{Nm}, F$ is actual value of force loading the tribological pair, $\mathrm{N}$, and $r_{1}$ is diameter of the counterspecimen, $\mathrm{m}$.

The calculated values were used for graphical presentation of friction coefficient in a function of force loading the tribological pair and friction distance.

Values of actual surface pressure at the contact point between the specimen and the counterspecimen were also determined. Calculations were made with formula (2), commonly used for determining pressures in slide bearings:

$$
p=\frac{F}{A},
$$

where $p$ is actual value of surface pressure, MPa, $F$ is actual value of force loading the tribological pair, $\mathrm{N}$, and $A$ is actual value of contact area between the specimen and the counterspecimen projected on the plane perpendicular to vertical axis of the counterspecimen, $\mathrm{m}^{2}$.

A result of wear of the specimen during its mating with the counterspecimen is trace of wear. Projection of this trace on the plane perpendicular to vertical axis of the counterspecimen is close to an ellipse (Figure 2), whose surface area can be determined when lengths of its axes are known.

Actual value of the parameter $A$ was determined from formula (3) in that actual lengths of the ellipse axes were 

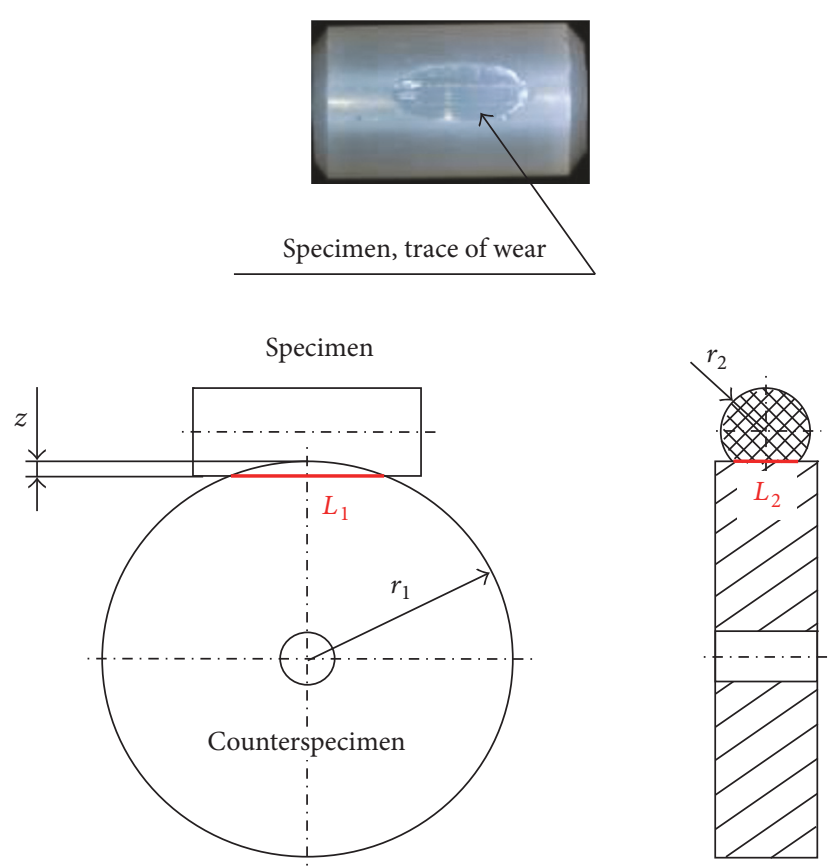

FIGURE 2: Specimen with trace of wear and axes of the ellipse being projection of the trace on the plane perpendicular to vertical axis of the counterspecimen: $z$, linear wear of the specimen; axis $L_{1}$, projected length of trace of wear; axis $L_{2}$, width of trace of wear.

related to actual value of linear wear of the specimen and to diameters of the specimen and the counterspecimen:

$$
\begin{aligned}
A & =\frac{\pi}{4} \cdot L_{1} \cdot L_{2} \\
& =\pi \cdot \sqrt{r_{1}^{2}-\left(r_{1}-z\right)^{2}} \cdot \sqrt{r_{2}^{2}-\left(r_{2}-z\right)^{2}}
\end{aligned}
$$

where $A$ is actual value of contact area between the specimen and the counterspecimen projected on the plane perpendicular to vertical axis of the counterspecimen, $\mathrm{m}^{2}, L_{1}$ and $L_{2}$ are lengths of the ellipse axes (projection of trace of wear), $\mathrm{m}, z$ is actual value of linear wear of the specimen, $\mathrm{m}, r_{1}$ is diameter of the counterspecimen, $\mathrm{m}$, and $r_{2}$ is diameter of the specimen, $\mathrm{m}$.

Initial value of the area $A$ was determined for linear wear of the specimen found after grinding-in.

It should be emphasised that, in the above calculations, a simplification concerning linear wear of the specimen $z$ was applied. Namely, value $z$ recorded during the test was applied in calculations and that value was composed of both material loss and deformation of the specimen caused by the force loading the friction pair.

After the tests, wear surfaces of the examined polymers were subjected to visual observations by means of a stereoscopic microscope and a scanning electron microscope in order to identify mechanisms of wear. In the case of polypropylene, SEM observations were carried out on an unmodified specimen, since otherwise there was a risk of damaging the microscope.

\section{Results of the Research}

4.1. Friction Coefficient. Wear rate is higher at a higher $p v$ value, where $p$ is contact pressure and $v$ is sliding speed [14]. The wear process is controlled to a greater extent by material transfer, which is a very characteristic phenomenon in contacts of polymers and plays the most important role in friction and wear processes in polymeric tribosystems [14].

Figure 3 shows representative curves of friction coefficient for PTFE, PA 6.6, PA $\mathrm{MoS}_{2}$, and unmodified and modified PP, tested at room temperature at sliding velocities of $0.13,0.26,0.44$, and $0.62 \mathrm{~m} \cdot \mathrm{s}^{-1}$, depending on sliding distance and load. The friction coefficient curve is a very important characteristic of the friction process. It should be noted that friction coefficient is also affected by sliding velocity through its effect on frictional heating. For all values of sliding velocity, impregnated PP showed an improvement in comparison to unmodified PP, PTFE, PA 6.6, and PA MoS 2 .

At the beginning it should be explained why, for polyamide PA 6.6 and PA $\mathrm{MoS}_{2}$, the lines illustrating values of friction coefficient in some diagrams (Figures 3(b)-3(d)) (like the lines illustrating friction torque, see Figures 4(b) and 4(c)) show distinct folds, while such folds do not occur for the other materials. For PA 6.6 and PA MoS 2 , the folds are present in most cases of the applied working velocities for higher load values (over $500 \mathrm{~N}$ ). These folds in the diagrams were caused by different behaviour of these materials in individual tests. Within high loads, friction torque recorded at a part of repetitions rapidly increased (during 5 to $7 \mathrm{~s}$ ), reaching the value of $350 \mathrm{Ncm}$, at which the stoppage of the test stand followed, and thus the given test was finished before the intended maximum load of the friction node could be reached (for polyamide PA 6.6 at $0.62 \mathrm{~m} \cdot \mathrm{s}^{-1}$ no specimen completed the test at the maximum permissible load). Of course, high values of friction torque were accompanied by high values of friction coefficient. However, such large growth of friction torque did not occur in other repetitions and measurements were continued till the planned maximum load of the friction node. The folds visible in the diagrams were caused by averaging actual values of friction coefficient obtained in individual tests, since large values of friction torque in the tests finished before reaching the maximum load were eliminated. Variability of friction coefficient, visible in the diagrams, indicates unstable operation of polyamide PA 6.6 and PA $\mathrm{MoS}_{2}$ in the tribological pair at its high loads.

At the smallest linear velocity $\left(0.13 \mathrm{~m} \cdot \mathrm{s}^{-1}\right)$ in relation to friction distance and increasing load, it can be seen that shapes of curves presenting changes of friction coefficient are similar for all the examined materials. At the beginning, values of friction coefficient increase rapidly and next stabilise, while this stabilisation occurs for individual materials at various moments, that is, at various friction distances and increasing load.

The largest friction coefficient and the latest stabilisation of its values were recorded for unmodified polypropylene. Beyond the set friction distance of ca. $25 \mathrm{~m}$ and load of ca. $400 \mathrm{~N}$, the friction coefficient is ca. 0.18 .

(In the context of test results, a name of a polymer always means the friction pair steel-polymer. However, in view of 


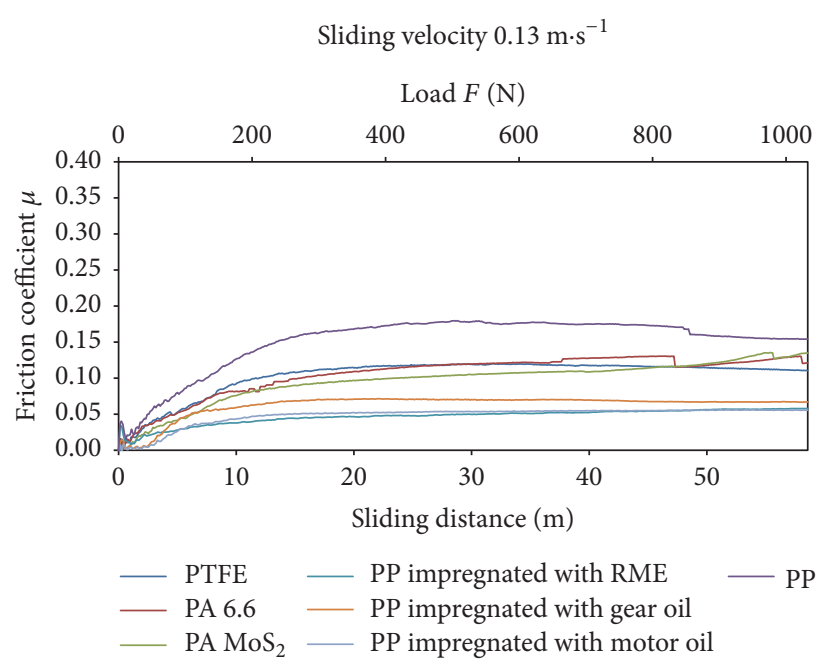

(a)

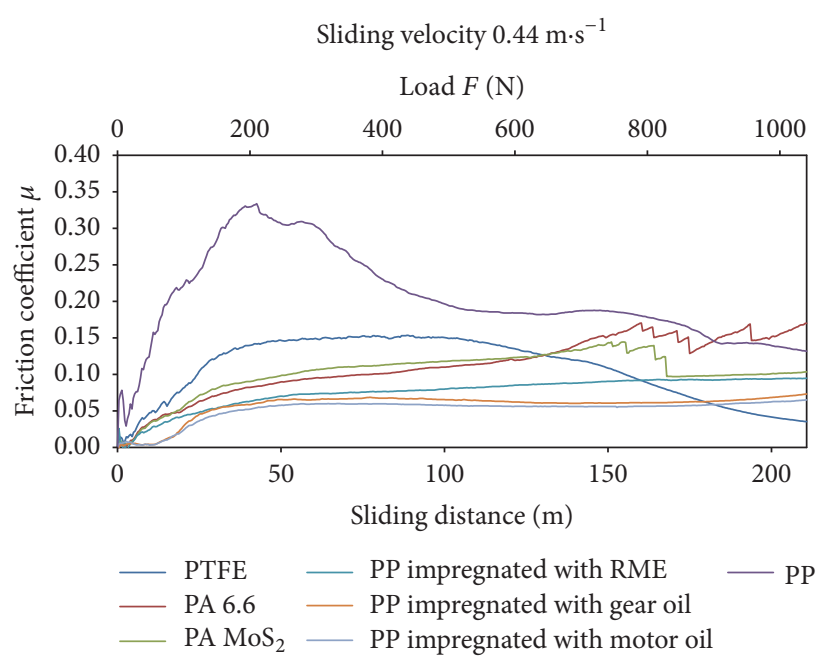

(c)

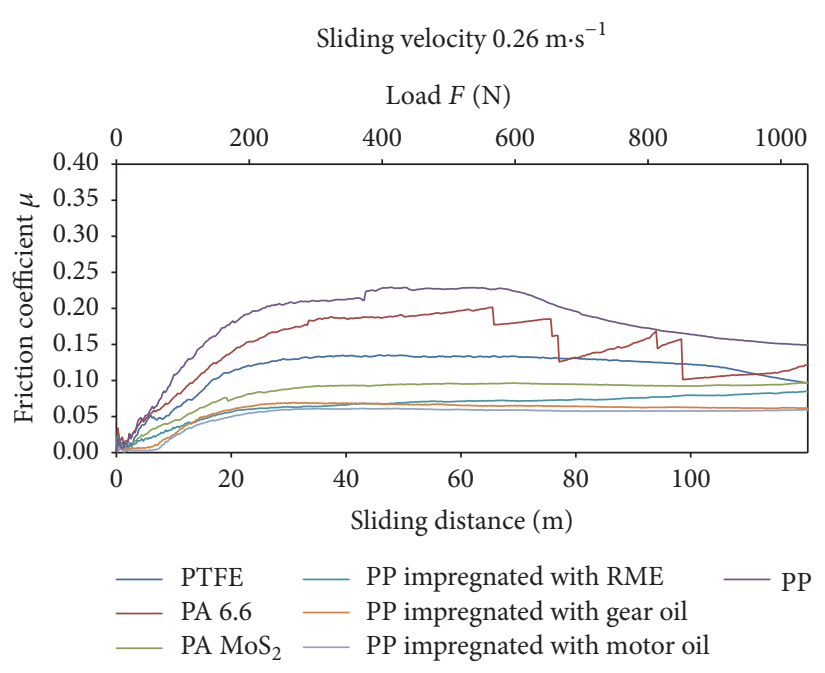

(b)

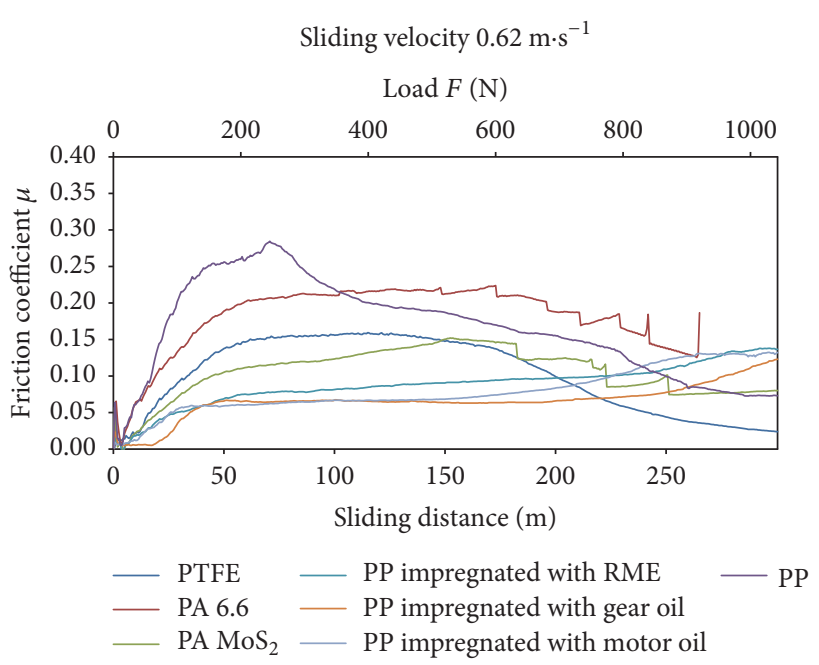

(d)

FIGURE 3: Relationship between sliding distance, load, and friction coefficient of the specimens at various sliding velocities: (a) 0.13 , (b) 0.26 , (c) 0.44 , and (d) $0.62 \mathrm{~m} \cdot \mathrm{s}^{-1}$.

better readability of the paper, a polymer name alone is used in the following text.)

It is interesting that shapes of friction curves for PA 6.6, PA MoS , and PTFE at $0.13 \mathrm{~m} \cdot \mathrm{s}^{-1}$ are similar (see Figure 3(a)). After stabilisation, friction coefficient ranges from ca. 0.11 for PTFE to over 0.12 for polyamides. Along with increasing load or friction distance, friction coefficient continually slightly increases for polyamides and decreases for PTFE. During abrasion of PTFE balls on glass plates at linear velocity of $0.1 \mathrm{~m} \cdot \mathrm{s}^{-1}$, Makinson and Tabor [15] also found high values of friction coefficient between 0.1 and 0.16 at the beginning of the test and next, after a determined friction distance, these values decreased, which was explained by a PTFE "filter" created as a result of its adhesion to the counterspecimen.

Analysis of friction curves for polypropylene only indicates a significant reduction of friction coefficient (Figure 3(a)) for polypropylene impregnated with oils in comparison to this parameter value for nonimpregnated polypropylene.
The lowest values were recorded for PP impregnated with RME and engine oil (0.05), but this value for the specimens impregnated with gear oil was not significantly higher (0.07). In comparison to unmodified PP, friction coefficient was reduced by $72 \%$ for RME and engine oil and by $61 \%$ for gear oil.

In the case of some polymers, twofold growth of linear velocity to $0.26 \mathrm{~m} \cdot \mathrm{s}^{-1}$ resulted in changed shapes of friction curves (see Figure 3(a)). This is especially visible for unmodified PP; the curve first rises (till friction distance ca. $20 \mathrm{~m}$ and load $200 \mathrm{~N}$ ) and next stabilises to descend slightly beyond ca. $70 \mathrm{~m}$ at $600 \mathrm{~N}$. For unmodified PP, friction coefficient in the stabilisation range is ca. 0.23 , nearly $30 \%$ higher than at $0.13 \mathrm{~m} \cdot \mathrm{s}^{-1}$.

For PA 6.6, friction coefficient quickly increases to ca. 0.18 (friction distance ca. $20 \mathrm{~m}$ and load nearly $300 \mathrm{~N}$ ) and then it grows decidedly slower and reaches 0.20 at friction distance $64 \mathrm{~m}$ and load $560 \mathrm{~N}$. In further ranges of friction distance 


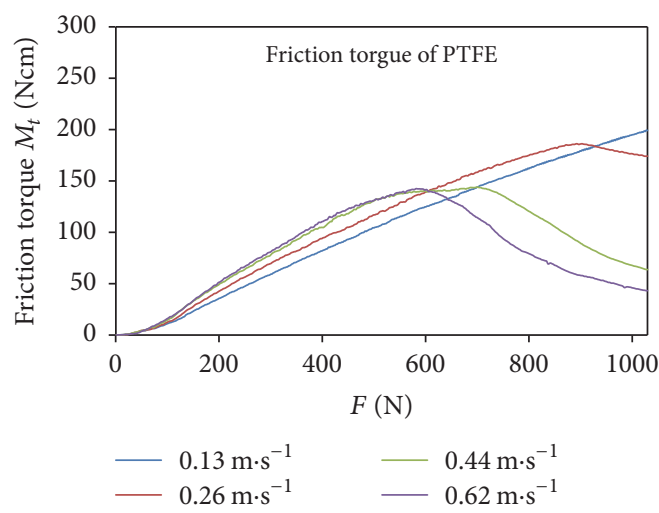

(a)
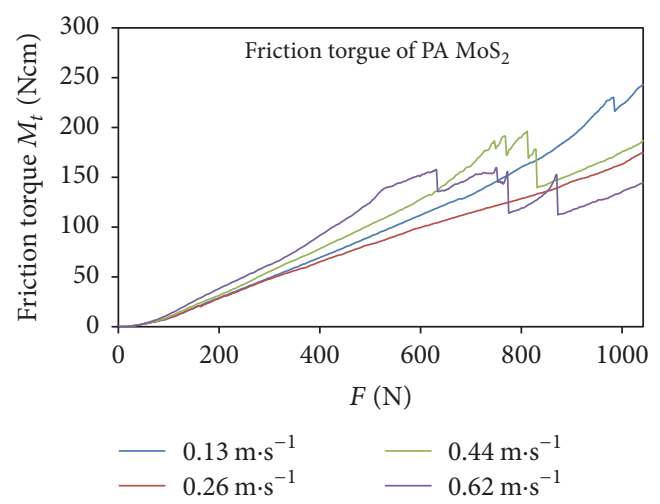

(c)

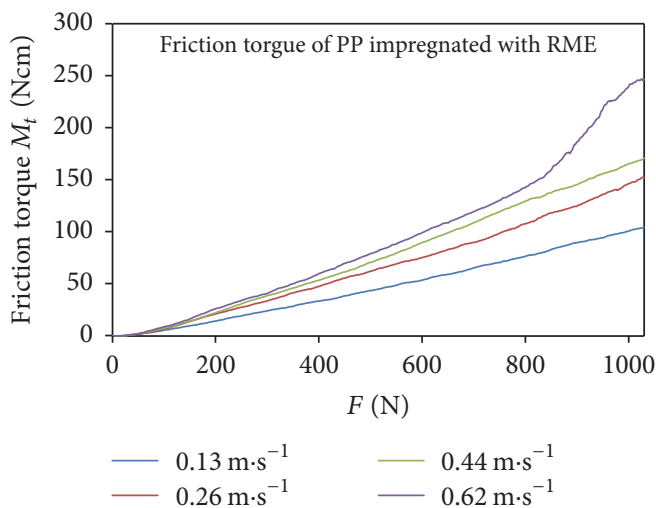

(e)

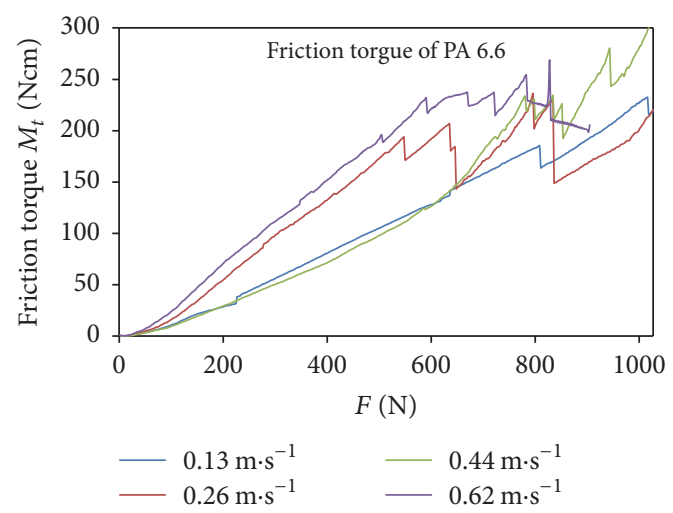

(b)

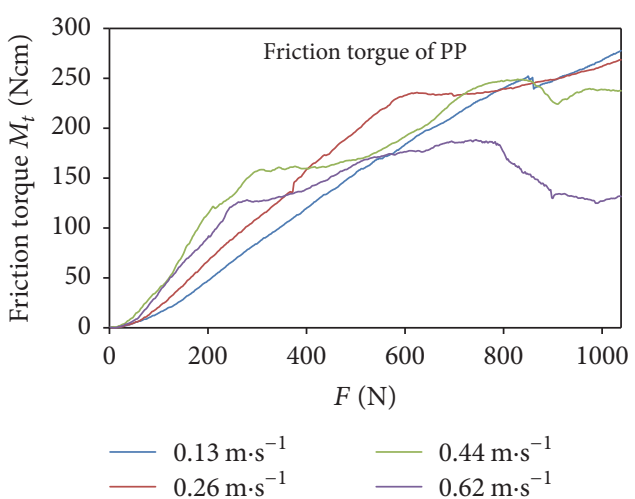

(d)

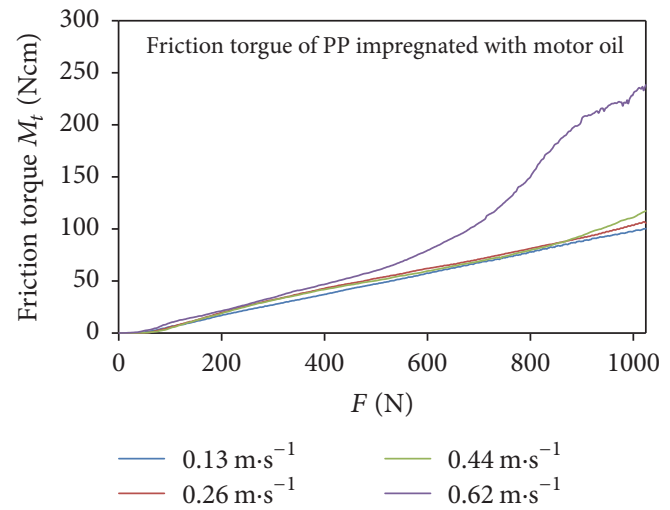

(f)

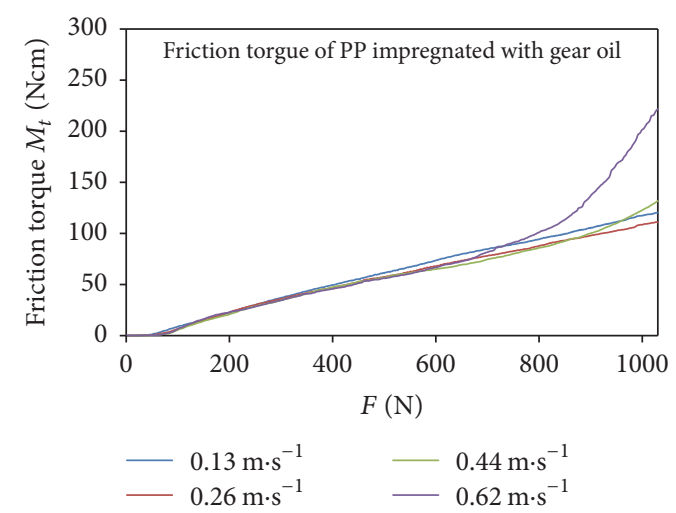

(g)

FIGURE 4: Relationship between sliding distance, load, and friction torque of the samples under various sliding velocities, $0.13,0.26,0.44$, and $0.62 \mathrm{~m} \cdot \mathrm{s}^{-1}$, for (a) PTFE, (b) PA 6.6, (c) PA $\mathrm{MoS}_{2}$, (d) unmodified PP, (e) PP impregnated with RME, (f) PP impregnated with engine oil, and (g) PP impregnated with gear oil. 
and load, the curve demonstrating friction coefficient of this material shows the previously described folds that indicate very different values of friction torque in individual runs and thus different values of friction coefficient. At this linear velocity $\left(0.26 \mathrm{~m} \cdot \mathrm{s}^{-1}\right)$, there are also differences between the curves for two examined polyamides PA 6.6 and PA $\mathrm{MoS}_{2}$. Friction coefficient of PA $\mathrm{MoS}_{2}$ is two times smaller than that of PA 6.6. The PA MoS 2 value approaches ca. 0.1 (also at friction distance ca. $20 \mathrm{~m}$ and load ca. $300 \mathrm{~N}$ ) and next stabilises. It should be also noted that the curve for $\mathrm{PA} \mathrm{MoS}$ at $0.26 \mathrm{~m} \cdot \mathrm{s}^{-1}$ is in the wide range similar to that obtained at $0.13 \mathrm{~m} \cdot \mathrm{s}^{-1}$.

In the case of PTFE, no significant differences were found in shapes of the friction coefficient curves. The only differences concerned the values themselves. At $0.26 \mathrm{~m} \cdot \mathrm{s}^{-1}$, friction coefficient was ca. $20 \%$ higher than that at $0.13 \mathrm{~m} \cdot \mathrm{s}^{-1}$. For this material, at both working velocities, a tendency to decreasing friction coefficient was found.

Impregnation with oils results in reduced friction coefficient of PP also at linear velocity of $0.26 \mathrm{~m} \cdot \mathrm{s}^{-1}$. Significantly lower values were found for the specimens made of impregnated PP. For lower sliding velocity, no significant changes in friction curves caused by impregnation with RME and engine and gear oils could be observed. Only a small reduction in friction coefficient was found in the case of PP impregnated with gear oil. The lowest value was found for PP impregnated with engine oil, but the value was not much higher than that for the specimens impregnated with RME and gear oil. Reduction of maximum friction coefficient in comparison to unmodified PP was 69\% for impregnation with RME and 73\% for impregnation with engine and gear oils.

Very different shapes of friction coefficient curves were found for sliding velocity of $0.44 \mathrm{~m} \cdot \mathrm{s}^{-1}$ in the case of unmodified PP, see Figure 3(c). Maximum value of 0.33 was found after sliding distance of $50 \mathrm{~m}$ at $200 \mathrm{~N}$. After that, the coefficient value dropped rapidly, showing two minimum values after sliding distances of $120 \mathrm{~m}$ and $180 \mathrm{~m}$, which corresponded to loads of $650 \mathrm{~N}$ and $900 \mathrm{~N}$. A characteristic feature of PP is its low thermal conductivity. Due to frictional heat, temperatures can easily reach melting point of the polymer and cause its surface melting. When the polymer melts, its friction coefficient decreases, according to the mechanism of thermally controlled friction [16].

It is also interesting that shapes of friction coefficient curves for PA 6.6 and PA $\mathrm{MoS}_{2}$ are similar. However, completely different shape of the curve is observed for PTFE. Modified PP still shows lower average maximum friction coefficient in comparison to unmodified PP (reduction after stabilisation is $73 \%$ for impregnation with RME and $82 \%$ for impregnation with gear and engine oils). In the case of impregnation with gear and engine oils, differences between friction coefficients are still very small. The values are similar to those for lower sliding velocity. Shapes of these curves for PP impregnated with engine and gear oils are nearly identical; small differences occur only for the specimens impregnated with RME, when friction coefficient after stabilisation is the highest. Decrease in friction coefficient can be explained by the Bekhet and Naga theory [17] according to the fact that friction force between surfaces of the thermoplastic and steel decreases during the sliding process due to increasing molecular orientation of the thermoplastic parallel to the sliding direction.

Friction curve for PP at linear velocity of $0.62 \mathrm{~m} \cdot \mathrm{s}^{-1}$ (Figure 3(d)) is similar to that found at $0.44 \mathrm{~m} \cdot \mathrm{s}^{-1}$, while maximum friction coefficient is lower at $0.62 \mathrm{~m} \cdot \mathrm{s}^{-1}$. This maximum value of 0.28 occurs after friction distance ca. $70 \mathrm{~m}$ at $250 \mathrm{~N}$. After reaching its maximum, friction coefficient quickly decreases, supposedly due to plasticization (fluidization) of the material, occurring at this working velocity and load higher than $250 \mathrm{~N}$. For PTFE as well, shape and values of friction curve are similar to those found at $0.44 \mathrm{~m} \cdot \mathrm{s}^{-1}$. In this case, maximum friction coefficient is ca. 0.15 .

For two examined polyamide grades, shapes of friction curves are similar, while friction coefficient values for these materials are different (see Figure 3(d)). In the stabilisation range, friction coefficient values for PA 6.6 and PA $\mathrm{MoS}_{2}$ are, respectively, ca. 0.22 and 0.15 . Variability of friction coefficient, demonstrated in the diagrams, shows instable mating of PA 6.6 and $\mathrm{PA} \mathrm{MoS}$ in the tribological pair at its high load.

Impregnated specimens still show the lowest values of maximum friction coefficient in comparison to unmodified PP, PTFE, and both polyamides. The coefficient values are not much higher than those achieved in the test with the lowest sliding velocity. However, a slight change was recorded in the diagrams of actual friction coefficient in function of friction distance and load. Friction coefficient of PP impregnated with gear oil reached stabilisation latest of all, and its value started increasing after friction distance ca. $250 \mathrm{~m}$ at $850 \mathrm{~N}$. The coefficient for the loads over $480 \mathrm{~N}$ was the lowest just for PP impregnated with gear oil. In the case of PP impregnated with engine oil, increase of the coefficient after stabilisation occurred earliest of all, as early as at $600 \mathrm{~N}$, which corresponds to friction distance of $150 \mathrm{~m}$. For PP impregnated with RME, stabilisation of friction coefficient lasted till $850 \mathrm{~N}$ and, for the whole test time, the value was the highest among the variants of modified PP.

Analysis of friction diagrams showed that impregnation of PP with oils improved friction conditions in contrast to dry friction that occurred in the case of unmodified PP, PTFE, and polyamides. This is clearly visible, especially for the specimens tested at low velocity, by reduced values of friction coefficient and its smaller variability.

4.2. Torque Moment. The quantity directly related to friction coefficient is friction torque. Figures $4(\mathrm{a})-4(\mathrm{~g})$ show friction torque for the examined polymers in function of linear velocity and loading force.

For PTFE (Figure 4(a)) at the lowest linear velocity $\left(0.13 \mathrm{~m} \cdot \mathrm{s}^{-1}\right)$, it can be assumed that friction torque increases linearly in relation to load of the node. It is similar at the other velocities, although linearity occurs up to some load (at 0.26 , 0.44 , and $0.62 \mathrm{~m} \cdot \mathrm{s}^{-1}$ it is, respectively, 850,600 , and $900 \mathrm{~N}$ ); after that friction torque value decreases.

In the case of PA $\mathrm{MoS}_{2}$ (Figure 4(b)), friction torque initially increases linearly with increasing load, reaching its lowest value in the test carried out at $0.26 \mathrm{~m} \cdot \mathrm{s}^{-1}$ and the 
highest value in the test at $0.62 \mathrm{~m} \cdot \mathrm{s}^{-1}$. However, at $0.62 \mathrm{~m} \cdot \mathrm{s}^{-1}$, friction torque shows high fluctuations at the load of ca. $600 \mathrm{~N}$ and higher. In similar way, at $0.44 \mathrm{~m} \cdot \mathrm{s}^{-1}$, high variability of friction torque starts from ca. $700 \mathrm{~N}$ (of course, similar fluctuations were recorded for actual values of friction coefficient, which was explained previously).

For PA 6.6 (Figure 4(b)), in each test carried out at any linear velocity, after initial linear increase with increasing load, friction torque shows large fluctuations. It is also interesting that no relation occurs between linear velocity and friction torque. Friction torque reaches its highest value at $0.62 \mathrm{~m} \cdot \mathrm{s}^{-1}$ and subsequently lower values at $0.26 \mathrm{~m} \cdot \mathrm{s}^{-1}, 0.13 \mathrm{~m} \cdot \mathrm{s}^{-1}$, and $0.44 \mathrm{~m} \cdot \mathrm{s}^{-1}$. For linear velocity of $0.62 \mathrm{~m} \cdot \mathrm{s}^{-1}$, friction torque shows high fluctuations when loading force reaches ca. $550 \mathrm{~N}$. Shape of friction torque curve is similar for linear velocity of $0.26 \mathrm{~m} \cdot \mathrm{s}^{-1}$. At $0.13 \mathrm{~m} \cdot \mathrm{s}^{-1}$, friction torque changes linearly with load force up to $800 \mathrm{~N}$.

Comparison of the curves for friction coefficient in relation to load for unmodified and impregnated PP (Figures $4(d)-4(g))$ shows that impregnation with oils significantly affects friction torque and behaviour of the materials during operation.

Friction torque of unmodified PP (Figure 4(d)) increases rapidly with load. The curves obtained for higher linear velocities show their maximum at ca. $800 \mathrm{~N}$ and then friction torque decreases, like it is for PTFE, although the values for $\mathrm{PP}$ are higher.

Behaviour of PP impregnated with oil is quite different (see Figures 4(e)-4(g)). Some regularity can be observed after impregnation with RME (Figure 4(e)). Namely, friction torque is the lowest for the lowest linear velocity and next it increases with increasing velocity. It is important to note that increased loading force results in almost directly proportional increase of friction torque and at linear velocity of $0.62 \mathrm{~m} \cdot \mathrm{s}^{-1}$ this proportionality disappears only from ca. $850 \mathrm{~N}$ up. Moreover, high similarity in shapes of torque curves for PP impregnated with engine and gear oils can be observed (Figures 4(f) and 4(g)). The differences appear only between the curves obtained for the highest linear velocity, that is, $0.62 \mathrm{~m} \cdot \mathrm{s}^{-1}$. It is important that no significant influence of linear velocity on friction torque was observed. This effect is visible only at linear velocity of $0.62 \mathrm{~m} \cdot \mathrm{s}^{-1}$ and only above some load values. The most important is that, at $0.13,0.26$, and $0.44 \mathrm{~m} \cdot \mathrm{s}^{-1}$, increase of friction torque is approximately directly proportional to loading force; therefore it is possible to foresee value of friction torque and thus behaviour of the so-modified PP on the grounds of load value.

4.3. Linear Wear. Figures 5(a)-5(d) show curves of linear wear of the examined polymers at various working velocities in relation to load force and friction distance that was different at individual velocities.

At $0.13 \mathrm{~m} \cdot \mathrm{s}^{-1}$, wear of unmodified PP as well as of PP impregnated with RME and gear and engine oils is in practice directly proportional to friction distance and loading force. However, the other examined materials (PA 6.6, PA $\mathrm{MoS}_{2}$, and PTFE) do not show such a regularity (Figure 5(a)). Wear is most intensive for PA MoS 2 and PP impregnated with RME but least intensive for unmodified PP. In the cases of PA 6.6 and PA MoS, occurrence of short moments of intensive wear was found. Wear of PTFE is proportional to friction distance and loading force up to the moment when load and friction distance reach responsibly ca. $480 \mathrm{~N}$ and $29 \mathrm{~m}$, and its value is comparable to those of $\mathrm{PA} \mathrm{MoS}_{2}$ and RME-impregnated $\mathrm{PP}$ and thus the materials, which at that sliding velocity were most intensively worn. However, in the further range of load and friction distance, this material was no longer subjected to wear (wear remained at the level of $0.7 \mathrm{~mm}$ ), which can be related to the phenomenon of strain hardening, described in [18].

Increase of velocity to $0.26 \mathrm{~m} \cdot \mathrm{s}^{-1}$ results in small changes in linear wear of the polymers (Figure 5(b)). It should be noted that wear curve of $\mathrm{PA} \mathrm{MoS}$ in Figure 5(b) coincides with that of PP impregnated with engine oil. It is interesting that wear of all the polymers except PTFE is nearly directly proportional to load force and friction distance. Like during the test at lower velocity, RME-impregnated PP and PTFE wear most intensively in the initial test range, while unmodified PP and PP impregnated with gear oil wear least intensively in that range. Initially, PTFE also wears proportionally to load and friction distance, and at ca. $380 \mathrm{~N}$ and ca. $45 \mathrm{~m}$ its wear is at the level of $0.5 \mathrm{~mm}$ and does not change in the further range. It is also interesting that wear values of the materials at 0.13 and $0.26 \mathrm{~m} / \mathrm{s}$ are similar, for PTFE even higher at lower velocity, though friction distance is then two times shorter. This looks as if load of the node played the key role here.

Important changes in wear intensity appear at linear velocity of $0.44 \mathrm{~m} \cdot \mathrm{s}^{-1}$ (Figure $5(\mathrm{c})$ ) when, like at $0.26 \mathrm{~m} \cdot \mathrm{s}^{-1}$, wear curve of PA MoS ${ }_{2}$ coincides with that of PP impregnated with engine oil. PP impregnated with RME and engine and gear oils still wears proportionally to load and friction distance, while PP impregnated with gear oil wears least intensively. However, the most intensively wearing material is PTFE whose wear is the largest from the moment when load force is ca. $100 \mathrm{~N}$ (which corresponds to friction distance of ca. $26 \mathrm{~m}$ ) and lasts to ca. $750 \mathrm{~N}$ (distance of ca. $150 \mathrm{~m}$ ). Linear wear of unmodified PP also proceeds in a different way; it can be assumed that initially PP wears almost proportionally to loading force and thus to friction distance, but the period of its very intensive wear begins after reaching ca. $880 \mathrm{~N}$.

Further changes in wear intensity occur at linear velocity of $0.62 \mathrm{~m} \cdot \mathrm{s}^{-1}$ (Figure 5(d)). Initially, linear wear of PP impregnated with three oils is nearly directly proportional to loading force. However, at higher load, its wear becomes more intensive (ca. $820 \mathrm{~N}$ for RME, ca. $830 \mathrm{~N}$ for engine oil, and ca. $950 \mathrm{~N}$ for gear oil). It was observed that wear of PA 6.6 and PP impregnated with gear oil proceeds most slowly. Wear curve for PA $\mathrm{MoS}_{2}$ is very similar to that obtained at $0.13 \mathrm{~m} \cdot \mathrm{s}^{-1}$. Shapes of linear wear curves for PTFE and unmodified PP are similar to shapes of the curves obtained at lower velocity, that is, $0.44 \mathrm{~m} \cdot \mathrm{s}^{-1}$. However, the value of load at that unmodified PP which wears intensively is lower and amounts to ca. $580 \mathrm{~N}$ (distance ca. $200 \mathrm{~m}$ ). The most intensively wearing material is PTFE whose wear is the largest when loading force reaches ca. $700 \mathrm{~N}$ (which corresponds to friction distance of ca. $200 \mathrm{~m}$ ). 


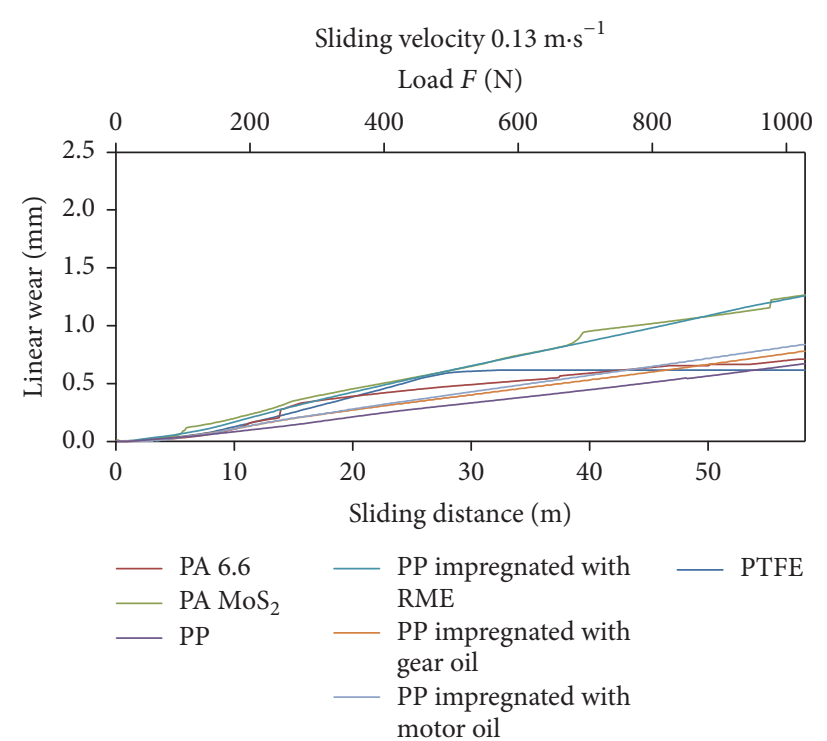

(a)

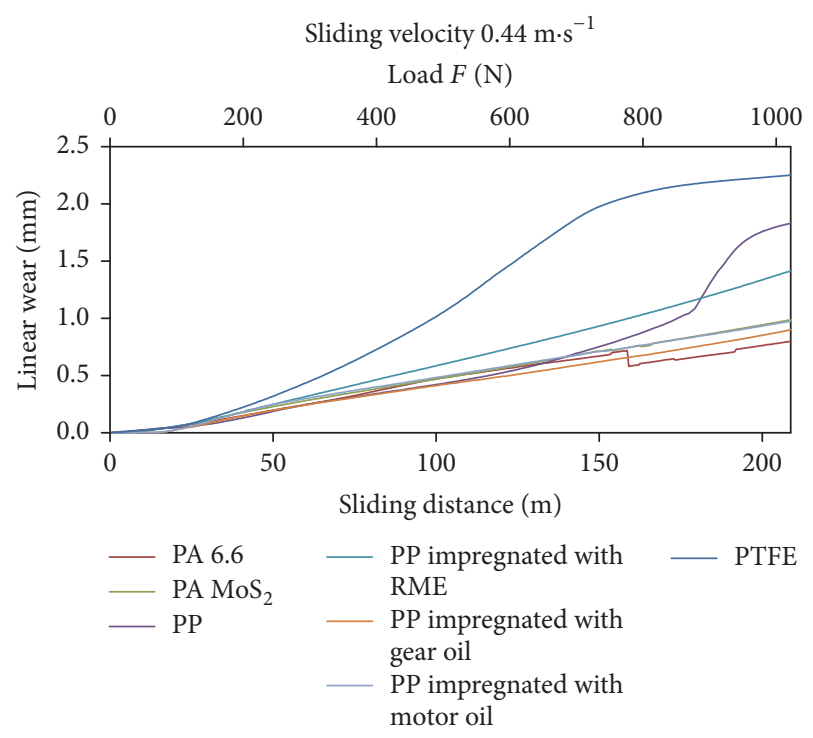

(c)

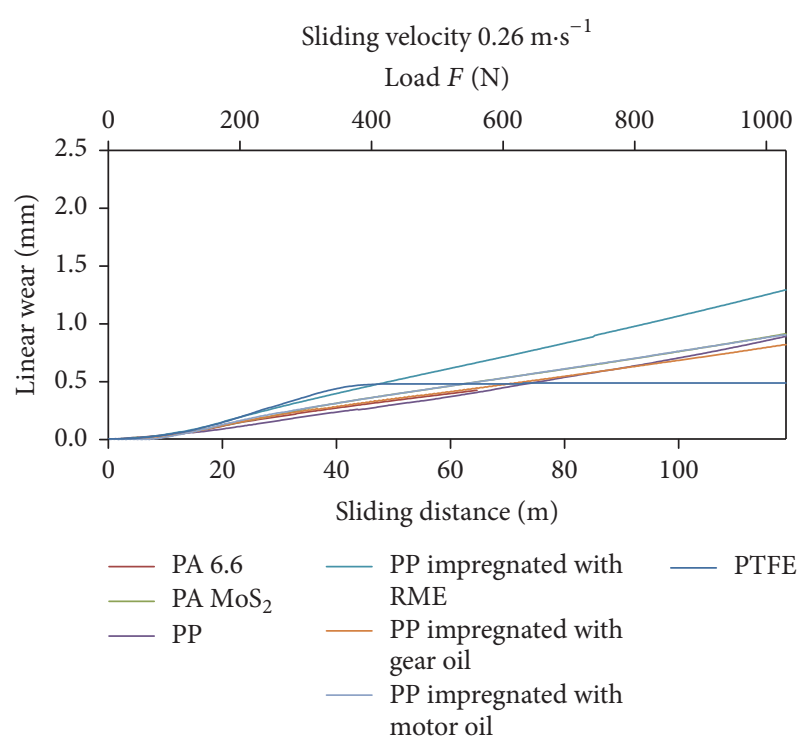

(b)

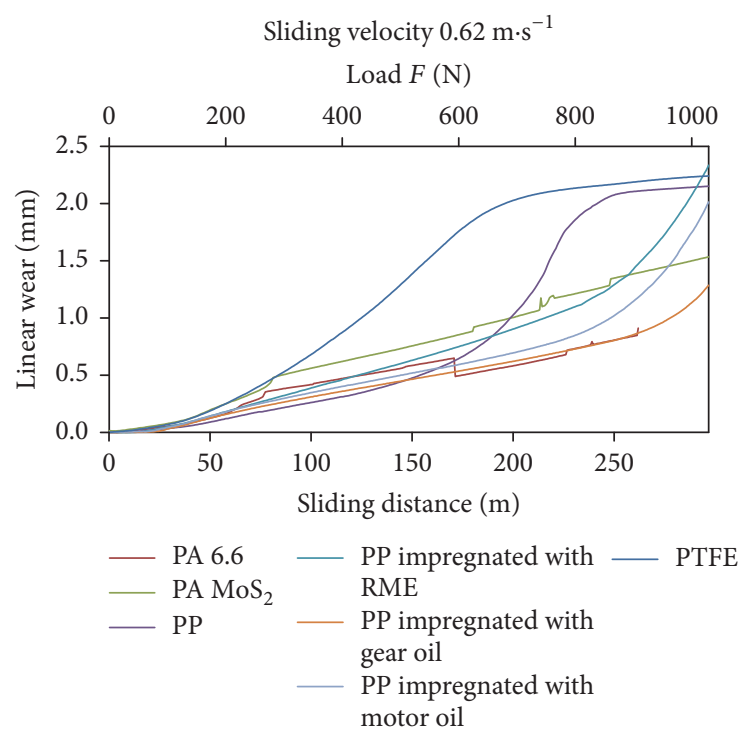

(d)

FIGURE 5: Relationship between sliding distance, load, and linear wear of the specimens under various sliding velocities: (a) 0.13, (b) 0.26, (c) 0.44 , and (d) $0.62 \mathrm{~m} \cdot \mathrm{s}^{-1}$.

Therefore, comparison of the results shows that wear of polypropylene impregnated with oils proceeds in more stable way, so it can be foreseen (of course, to some load values) and controlled.

Values of absolute mass consumption of the tested components are shown in Figure 6. At sliding velocities of 0.13, 0.26 , and $0.44 \mathrm{~m} \cdot \mathrm{s}^{-1}$, absolute mass consumption was very high for PTFE. These results confirm also the fact known in tribology that Teflon has low friction coefficient but very poor scratch resistance [19]. In the case of PTFE, intensive wear was observed even at sliding velocity of $0.13 \mathrm{~m} \cdot \mathrm{s}^{-1}$. It should be also noted that, at $0.13,0.26$, and $0.44 \mathrm{~m} \cdot \mathrm{s}^{-1}$, PA 6.6, PA $\mathrm{MoS}_{2}$, and PP impregnated with gear and engine oils showed absolute mass consumption between 0.001 and 0.003 g. Similar values were also recorded for PA 6.6 at
$0.62 \mathrm{~m} \cdot \mathrm{s}^{-1}$. At sliding velocities of 0.44 and $0.62 \mathrm{~m} \cdot \mathrm{s}^{-1}$, PTFE and unmodified PP reached high values of relative mass consumption, which was caused by significant linear wear of the materials. For unmodified PP, variation of wear is nonlinear and dramatically increases up to $0.44 \mathrm{~m} \cdot \mathrm{s}^{-1}$. At sliding velocity of $0.62 \mathrm{~m} \cdot \mathrm{s}^{-1}$, PP impregnated with engine oil and RME showed very high absolute mass consumption. In contrast to unmodified PP, PP impregnated with gear oil was characterized by lower values of linear wear and absolute mass consumption during the tests at 0.44 and $0.62 \mathrm{~m} \cdot \mathrm{s}^{-1}$. Reduction of wear provided by a film of lubricant is especially visible at linear velocity of $0.62 \mathrm{~m} \cdot \mathrm{s}^{-1}$.

4.4. Pressures. Comparison of the obtained pressure values occurring on contact surfaces of friction pairs is shown in 


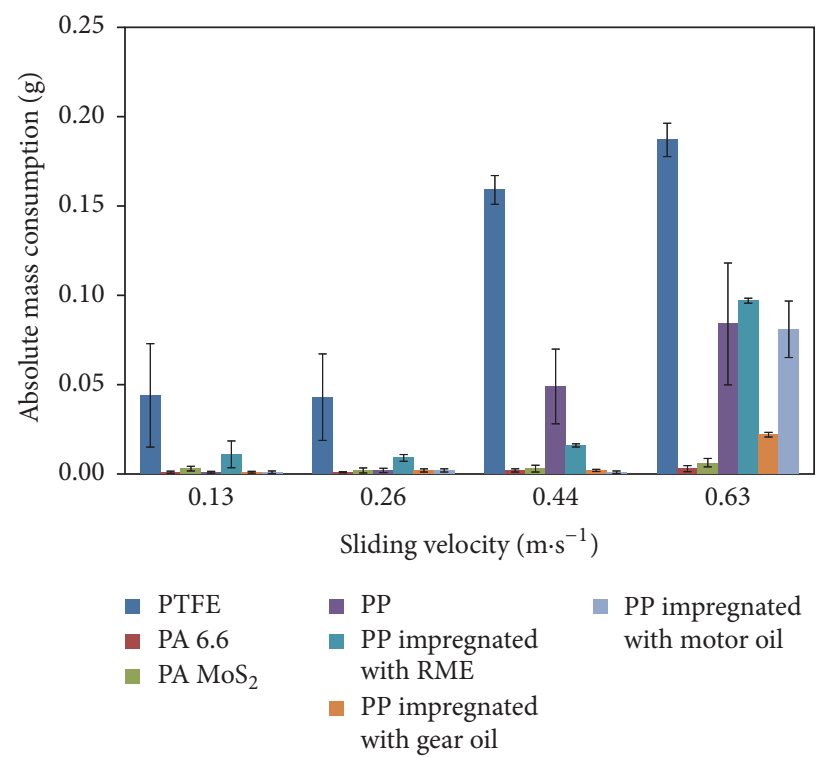

FIgURE 6: Average value of absolute mass consumption of the tested polymers for various sliding velocities: $0.13,0.26,0.44$, and $0.62 \mathrm{~m} \cdot \mathrm{s}^{-1}$.

Figure 7. For PP impregnated with engine and gear oils, at each velocity, the highest pressures were always observed in initial periods of tests. For these two materials, the highest pressure reaching almost $140 \mathrm{MPa}$ occurred during the test carried out at $0.26 \mathrm{~m} \cdot \mathrm{s}^{-1}$. Increased pressures for these two modified PPs result from the fact that no linear wear occurs at initial sliding phase and the contact area obtained during grinding-in is kept unchanged. The no-wear period is observed until the load force reaches $50 \mathrm{~N}$ to $66 \mathrm{~N}$, depending on linear velocity. This effect could be explained by creation, between the specimen and the counterspecimen, of a boundary layer composed of adsorbed molecules of oil used for impregnation. Such a layer is probably created during grinding-in. The engine and gear oils contain additives improving their lubrication performance and RME contains no such additives. This could explain the fact that no pressure increase was observed for the specimens impregnated with RME. The boundary layer becomes destroyed only after the above-mentioned load is exceeded and then the wear process begins, accompanied by decreasing pressure value.

It is interesting that when loading force exceeds ca. $200 \mathrm{~N}$ at each working velocity, pressure value stabilises and remains roughly unchanged in spite of increasing loading force. An exception is the friction pair PTFE-steel during work at the velocity of 0.13 and $0.26 \mathrm{~m} \cdot \mathrm{s}^{-1}$, for which, with the increase of load, the pressures slightly increased. In general, stabilisation of pressure during the tests indicates that increase of load is accompanied by adequate increase of contact area of mating materials, resulting in maintaining pressure values on an even level.

For all the examined materials and working velocities, at loading forces higher than ca. $200 \mathrm{~N}$, pressure values did not exceed $30 \mathrm{MPa}$. During the tests, the lowest pressures during their stabilisation period were recorded at 0.13 and $0.26 \mathrm{~m} \cdot \mathrm{s}^{-1}$ for PTFE, RME-impregnated PP, and PA $\mathrm{MoS}_{2}$, at $0.44 \mathrm{~m} \cdot \mathrm{s}^{-1}$ for PTFE, unmodified PP, and RME-impregnated PP, and at $0.62 \mathrm{~m} \cdot \mathrm{s}^{-1}$ for PTFE and PA $\mathrm{MoS}_{2}$.

4.5. Temperature. During the tests, temperature of each specimen was measured with a thermocouple. For technical reasons, temperature during the tests was measured at some distance from the contact area, which was mentioned in the section concerning methodology. However, it can be assumed that temperature changes at the contact point between a specimen and a counterspecimen are similar to those measured. Of course, temperature values themselves at the contact point are higher. Figures $8(a)-8(d)$ show temperature changes in relation to friction distance, load, and linear velocity. As can be seen, temperature increased along with elapsed time, which corresponds with increasing load and friction distance. Similarly, at higher working velocities, larger temperature increments were observed. At the lowest linear velocity, temperature increments were roughly comparable, but for the velocity of $0.26 \mathrm{~m} \cdot \mathrm{s}^{-1}$ up, the largest increments were recorded for unmodified PP and PTFE (Figure $8(\mathrm{~b})$ ). The largest temperature increments for unmodified PP and PTFE are maintained also at $0.44 \mathrm{~m} \cdot \mathrm{s}^{-1}$ (Figure $8(\mathrm{c})$ ). In turn, for the highest linear velocity of $0.62 \mathrm{~m} \cdot \mathrm{s}^{-1}$, the largest temperature increments were observed also for PA 6.6 (Figure 8(d)). Moreover, it can be seen that these rapid temperature growths correspond to the above-described changes of friction coefficient and friction torque. Therefore, it can be said that the phenomena occurring in a friction pair are to a large degree controlled by the processes related to temperature increase.

4.6. Wear Surface. Figure 9 shows general condition of surfaces of the tested polymers, and Figures 10-13 show images of worn surfaces, obtained with use of a scanning electron microscope. According to Brostow et al. [4] "sometimes it is mistakenly assumed that interfaces with high friction show a high rate of wear. This is not generally true; both friction and wear have to be determined. There are cases when solid interfaces of polymers show relatively low friction but fairly high wear. Wear of a material can be mechanical and/or chemical; it is generally accelerated by heating during friction. Wear mechanism can be adhesion, abrasion, fatigue and the effect of erosion, chemical reactions including corrosion, or else an induced electric arc. Fairly often there is no single mechanism of wear but a combination of several mechanisms."

4.7. Wear Surface of PTFE. After testing at $0.13 \mathrm{~m} \cdot \mathrm{s}^{-1}$, surface of the PTFE specimen shows small marks of wear in form of parallel scratches (see Figure 10(a)). The surface is porous. It was observed at the boundary line between worn and unworn surfaces that the polymer material is plastically deformed by the counterspecimen and next is displaced towards the edge (Figure 10(b)). Twofold increase of linear velocity results in qualitative changes of the wear surface (Figure 10(c)). First of all, increased number of pores was found. Therefore, porosity is not a specific feature of the examined material but results from the existing mechanism of wear. Localised wear areas are present on the surface, indicating that the material is 


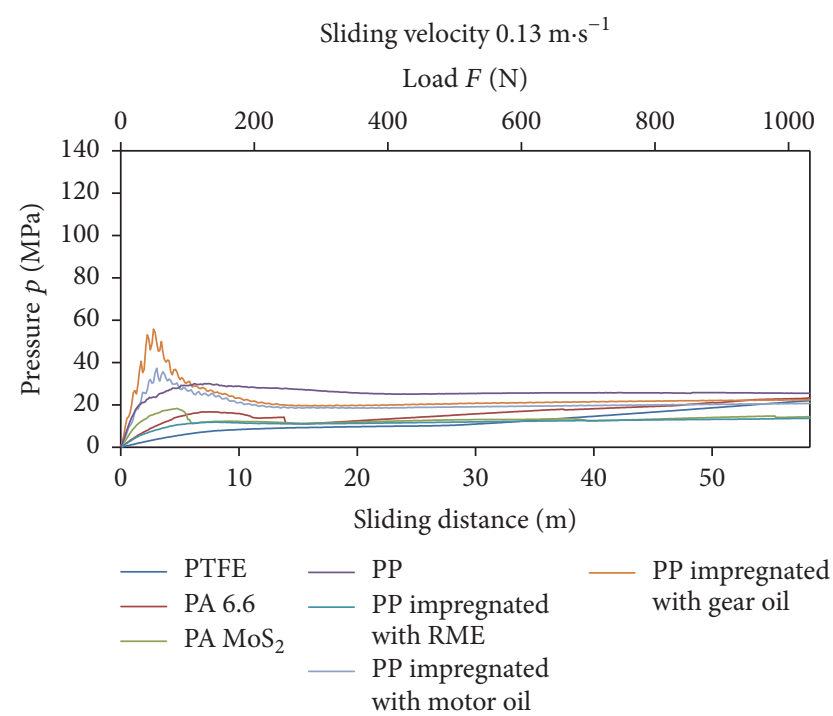

(a)

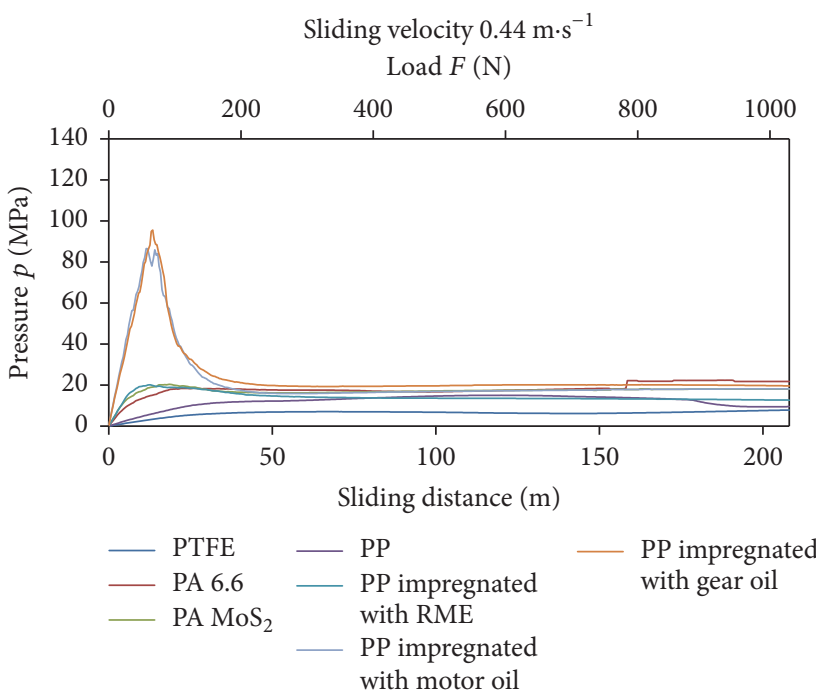

(c)

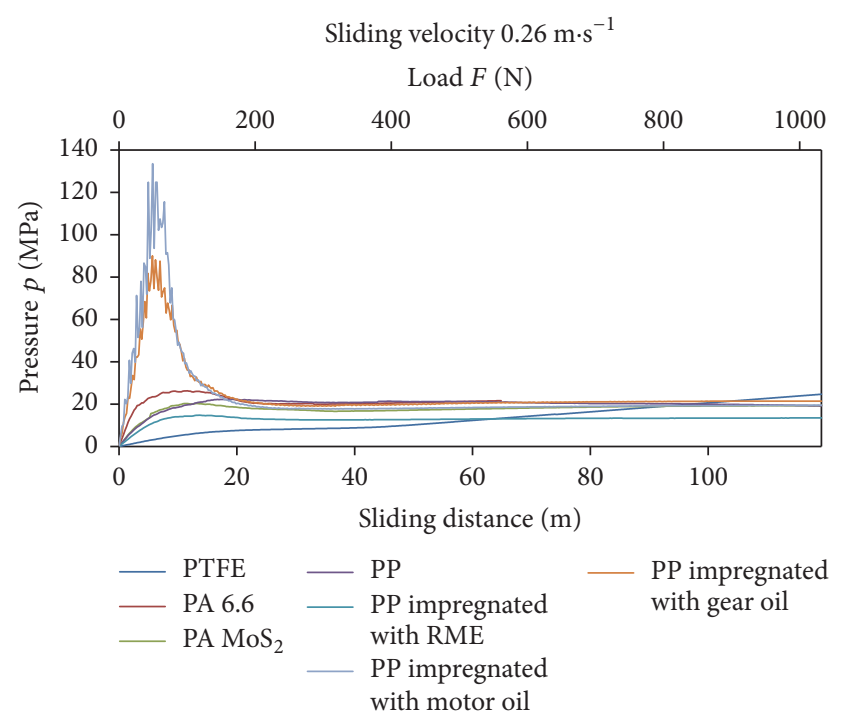

(b)

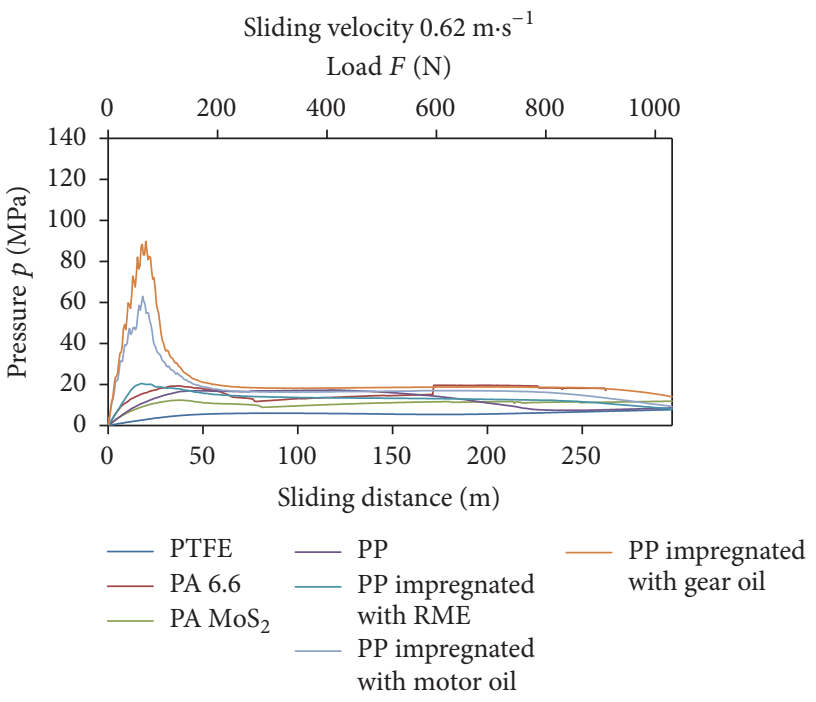

(d)

FIGURE 7: Relationships between sliding distance, load, and pressure of the samples under various sliding velocities: (a) 0.13 , (b) 0.26 , (c) 0.44 , and (d) $0.62 \mathrm{~m} \cdot \mathrm{s}^{-1}$.

plastically deformed, which can result in enlargement of the existing pores. This is especially visible on the exemplary surface after the test at $0.44 \mathrm{~m} \cdot \mathrm{s}^{-1}$ (Figures $10(\mathrm{~d})$ and $10(\mathrm{e})$ ). It can be seen that the material is plastically deformed and next removed, which results in increased size of discontinuities (Figure 10(e)). Probably, in a further phase, the so-displaced material is torn off as a result of its fatigue. This mechanism of wear results in significant material losses and, consequently, in the largest mass wear among all the tested specimens. Increase of linear velocity to $0.62 \mathrm{~m} \cdot \mathrm{s}^{-1}$ (Figure 10(f)) did not result in any qualitative change of wear surface in comparison to the surface obtained at $0.44 \mathrm{~m} \cdot \mathrm{s}^{-1}$.

4.8. Wear Surface of PA 6.6. Cracks, tiny parallel scratches, and wear products pressed in the surface were observed on surfaces of PA 6.6 specimens tested at 0.13 and $0.26 \mathrm{~m} \cdot \mathrm{s}^{-1}$ (see Figures 11(a) and 11(b)). The cracks could be caused by tearing off the material adhesively joined with the counterspecimen.

Increase of linear velocity to $0.44 \mathrm{~m} \cdot \mathrm{s}^{-1}$ results in qualitative changes on surface of the examined material (Figure 11(c)). The surface becomes smooth and overlaps of the material appear here and there, named in literature as "rollshaped particles" [6]. However, their accumulation is small.

On the surface of the specimen tested at the highest velocity $\left(0.62 \mathrm{~m} \cdot \mathrm{s}^{-1}\right)$, occurrence of a zone with "scaly" structure was found, formed of "roll-shaped particles" that are much more numerous and finer in comparison to those present on the specimen tested at a lower velocity (Figures $11(\mathrm{~d})$ and 11(e)). The authors of [6] state the following: "Frictional work presumably induces the formation of wear particles. Plastic 


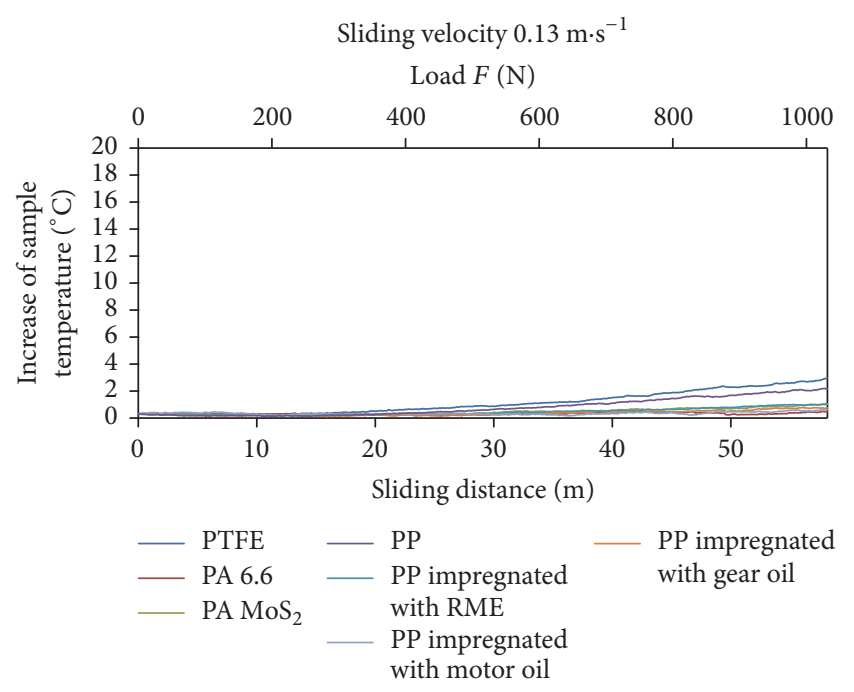

(a)

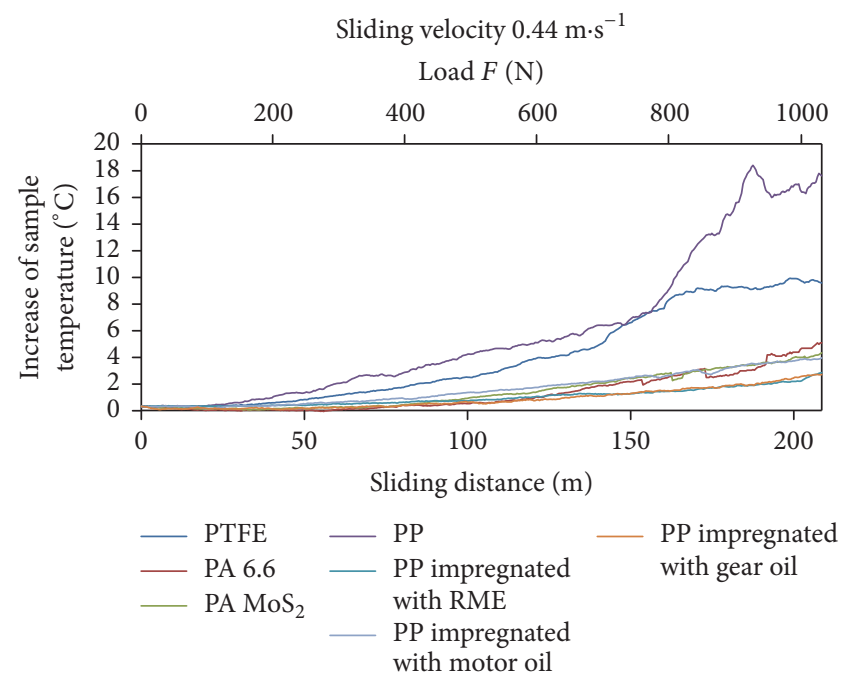

(c)

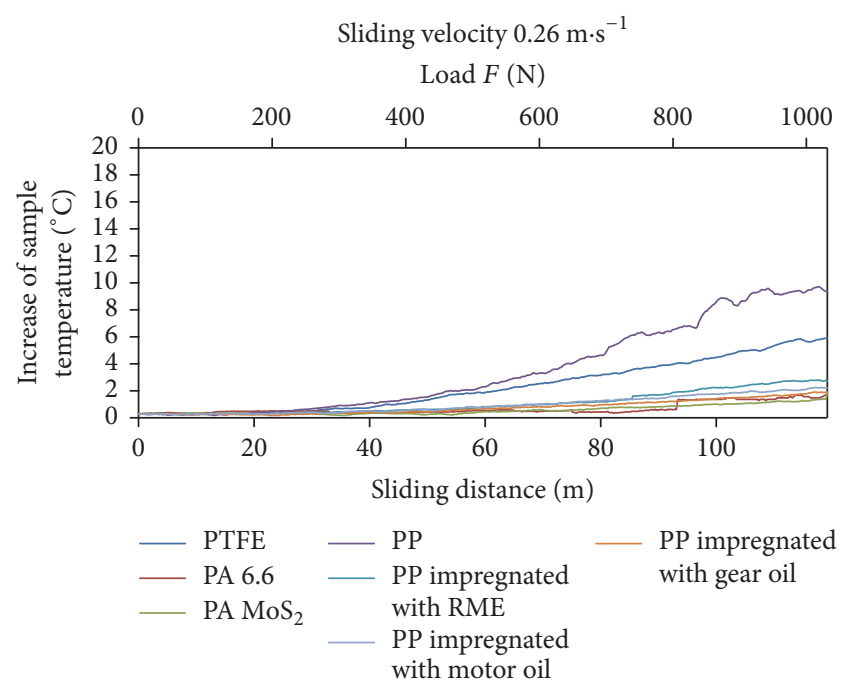

(b)

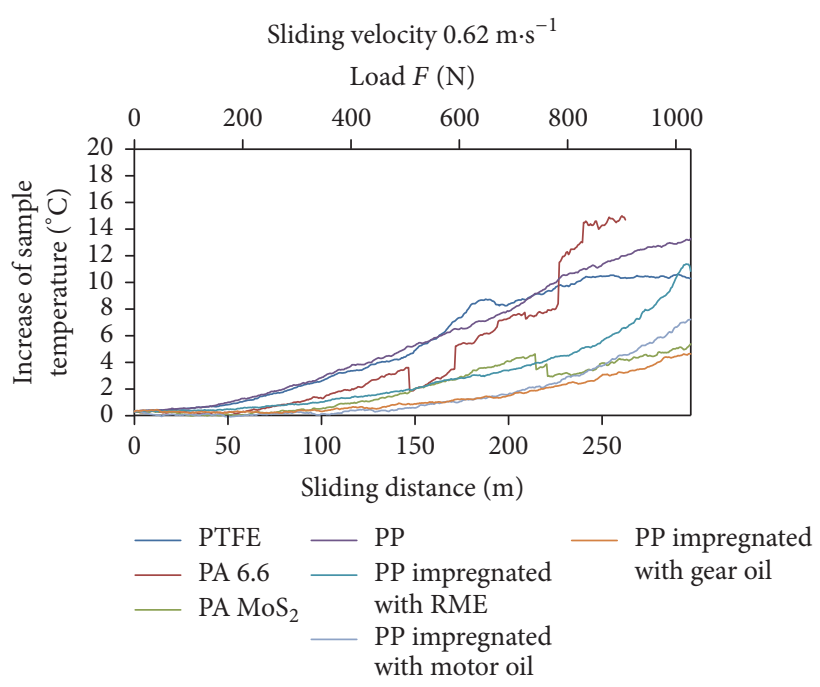

(d)

FIGURE 8: Relationships between sliding distance, load, and temperature of the specimens under various sliding velocities: (a) 0.13 , (b) 0.26 , (c) 0.44 , and (d) $0.62 \mathrm{~m} \cdot \mathrm{s}^{-1}$.

flow was considered to affect the formation of the 'roll-shaped particles.' However, the main cause of generation of rollshaped particles was considered to be a local surface breaking because of high friction. These wear particles agglomerated as roll-shaped particles and were removed to the outside of the wear track." This means that, in this case, heat generated during a test at higher linear velocity caused local partial melting and plastic flow of the examined material. So, at $0.62 \mathrm{~m} \cdot \mathrm{s}^{-1}$, the material was plastically deformed and then displaced according to the friction direction. In consequence, "roll-shaped particles" appeared on the specimen surface. As a result of fatigue, these particles were next separated from the surface and removed as wear products.

4.9. Wear Surface of PA MoS 2 . Analysis of worn surfaces of the tested PA MoS 2 specimens indicates that they are similar to those of the PA 6.6 specimens. So, a similar mechanism of wear can be considered here. A zone with scaly structure is dominating, formed of "roll-shaped particles" much more numerous and larger in comparison to those occurring on surfaces of PA 6.6 specimens (Figures 12(a)-12(d)). It is interesting that the lower the linear velocity is, the larger surface is occupied by the particles but, at the same time, the particles are more flat and adhere to the wear surface (Figures $12(\mathrm{a})$ and $12(\mathrm{~b}))$. As linear velocity increases, more material is removed from the wear surface, plastically deformed and drawn according to rotation direction of the counterspecimen (Figure 12(d)). As a result, "roll-shaped particles" are formed, as was mentioned before, similar to those created on surfaces of PA 6.6 specimens. It can be supposed that formation of "roll-shaped particles" could contribute to large fluctuations of the previously described friction torque and friction coefficient and thus to unstable behaviour of the examined polyamides. 


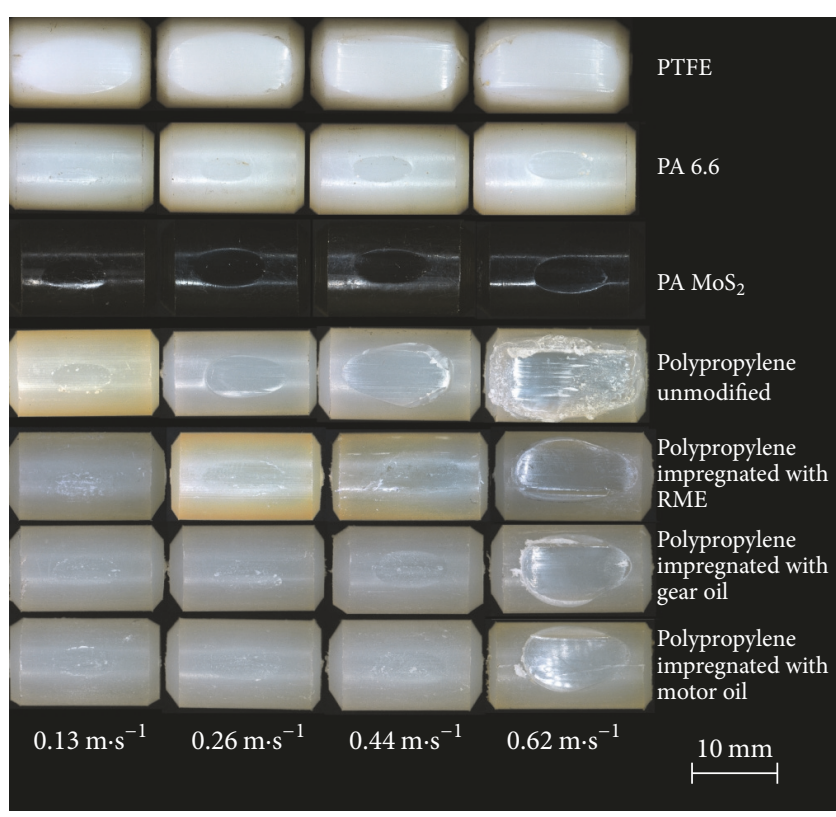

FIGURE 9: Effect of sliding velocity on worn surfaces of the tested specimens.

4.10. Wear Surface of PP. It was found for unmodified PP that, depending on linear velocity, various mechanisms are active, resulting in various intensities of wear. This is especially visible at $0.62 \mathrm{~m} \cdot \mathrm{s}^{-1}$, when the specimen surface showed significant traces of wear.

At $0.13 \mathrm{~m} \cdot \mathrm{s}^{-1}$, wear surface of unmodified PP is smooth and shallow scratches are arranged in parallel (Figure 13(a)). Traces of wear of adhesive nature were also seen, but particles of worn material joined to surface could be only observed, creating characteristic islands protruding over the smooth surface. A similar adhesive mechanism of wear was noted for the specimens tested at higher linear velocities, that is, 0.26 and $0.44 \mathrm{~m} \cdot \mathrm{s}^{-1}$ (Figures 13(b) and 13(c)). At higher velocity of $0.44 \mathrm{~m} \cdot \mathrm{s}^{-1}$, scratches became deeper and local cracks occurred on the wear surface (Figure 13(c)).

Mechanism of wear of unmodified PP changes, when linear velocity increases to $0.62 \mathrm{~m} \cdot \mathrm{s}^{-1}$ (Figures $13(\mathrm{~d})-13(\mathrm{f})$ ). At $0.13,0.26$, and $0.44 \mathrm{~m} \cdot \mathrm{s}^{-1}$, it could be seen that the main mechanism of wear was adhesion and microcutting. However, at $0.62 \mathrm{~m} \cdot \mathrm{s}^{-1}$, wear surface of the specimens can be divided into two zones: smooth zone dominated (like before) by adhesion and microcutting (Figure 13(d)) and the zone being a clear fracture with plastic deformation (Figures 13(e) and 13(f)). The zone with a fracture is characterised by highly developed topography with fibrous structure. The fibres create bridges with plastically deformed pores occurring between them. Moreover, it could be seen that a part of the material was cut off from the specimen surface and displaced to the edge of the wear surface.

At low linear velocity, small amount of work is converted to heat. This changes, when sliding velocity increases. Heat generated in this case results in local melting of the material and its plastic flow according to the forcing factors occurring in the friction node. For unmodified PP, thermal wear occurs when linear velocity increases over $0.44 \mathrm{~m} \cdot \mathrm{s}^{-1}$.

Analysis of changes of friction coefficient in function of friction distance at various sliding velocities indicates that thermal wear of PP impregnated with oils did not occur even at $0.62 \mathrm{~m} \cdot \mathrm{s}^{-1}$. So, the conclusion can be drawn that impregnation with oils protects propylene against catastrophic wear that takes place during thermal wear. This phenomenon can be explained by decrease of oil viscosity with increasing operating temperature [20]. For example, Couronné et al. [21] and Cousseau et al. [22] reported significant lubricant starvation of ester-based greases thickened with lithium, since this type of grease has a high flow index.

\section{Discussion}

Within the presented research, influence of modification of polypropylene by impregnation with oils on friction coefficient and wear was determined during their operation at sliding friction without lubrication. These parameters were compared with those of unmodified polypropylene, Teflon, and polyamides. Impregnation with oils significantly affected friction coefficient and friction torque of the examined polypropylene, decreasing values of these parameters. Figure 14 shows ratios of friction coefficient values found for the examined polymers. The presented values are average values from ratios of the coefficient determined at individual measuring points, that is, occurring at individual loads of the friction pairs. The authors realise the simplification applied at such calculations, but it seems that their results can serve for demonstrative evaluation of influence of impregnating PP with oils on friction coefficient. Clearly visible is reduction of friction coefficient value as a result of such modification of PP: the found general friction coefficient of oil-impregnated polypropylene is 2.2 to 5.3 times lower. At the same time, general friction coefficient of oil-impregnated PP was found to be 1.3 to 3.2 times lower in comparison to PTFE, PA 6.6, and $\mathrm{PA} \mathrm{MoS}$. It should be added that friction coefficient of unmodified PP is 1.0 to 2.0 times higher in comparison to PTFE, PA 6.6, and PA MoS .

However, it was found on the grounds of the recorded linear wear of the examined polymers that, in the range of low and medium loads of the friction pair, unmodified PP was characterised by the highest wear resistance. Wear of oilimpregnated PP was higher than that of unmodified polymer. The smallest differences occurred in the case of impregnation with gear oil and the largest for impregnation with RME, which can be related to absence of additives improving lubricity and to possible influence of RME on properties of the polymer [12]. In general, such regularity occurred at lower sliding velocities $\left(0.13\right.$ and $\left.0.26 \mathrm{~m} \cdot \mathrm{s}^{-1}\right)$ and, at low or medium range of loads, at higher sliding velocities ( 0.44 and $\left.0.62 \mathrm{~m} \cdot \mathrm{s}^{-1}\right)$. The situation was reversed in the range of high loads and higher velocities. In that range, wear of unmodified PP increased drastically, definitely exceeding wear value of impregnated material. It should be added that wear of PP impregnated with engine oil and gear oil was slightly lower or comparable to that of other tested polymers (PTFE, $\mathrm{PA} \mathrm{MoS}$, and PA 6.6), while PTFE at initial load range was subjected to 


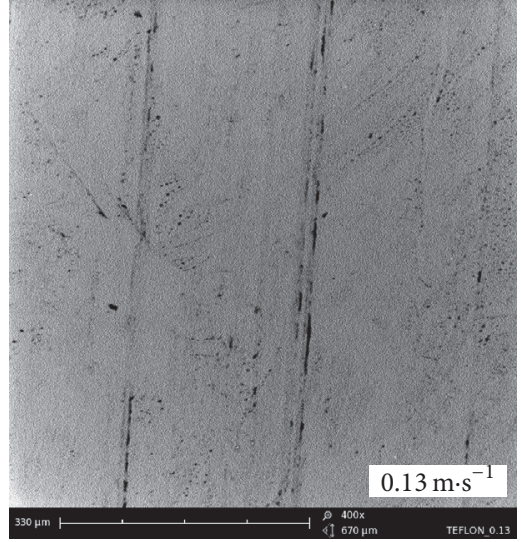

(a)

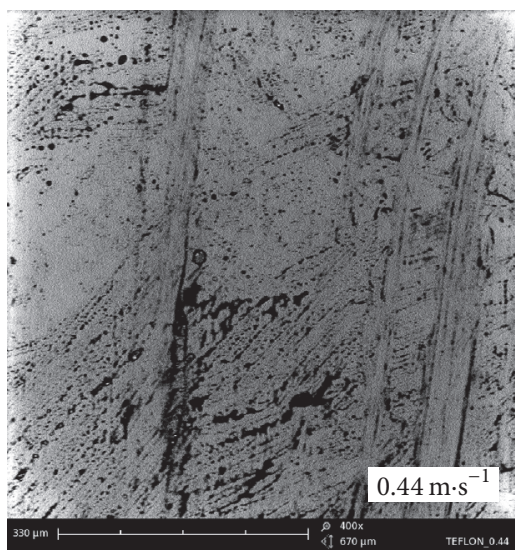

(d)

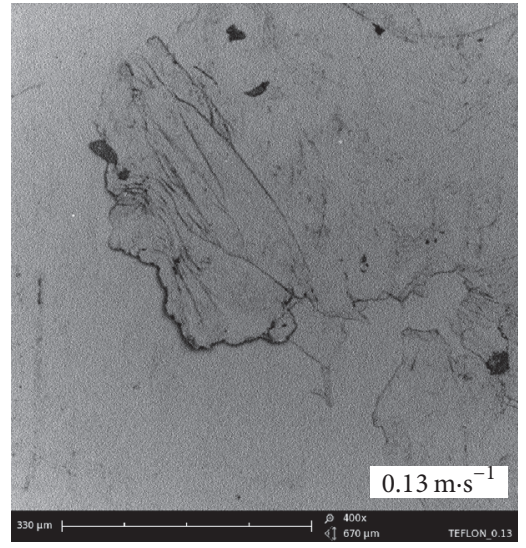

(b)

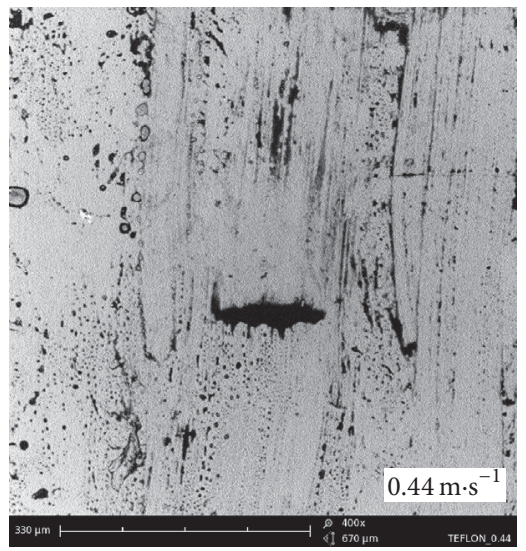

(e)

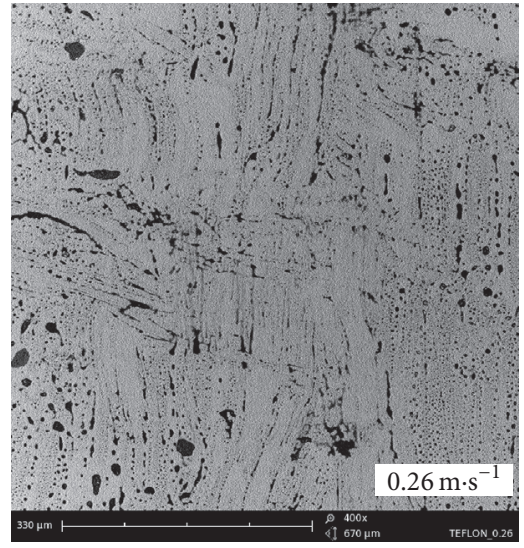

(c)

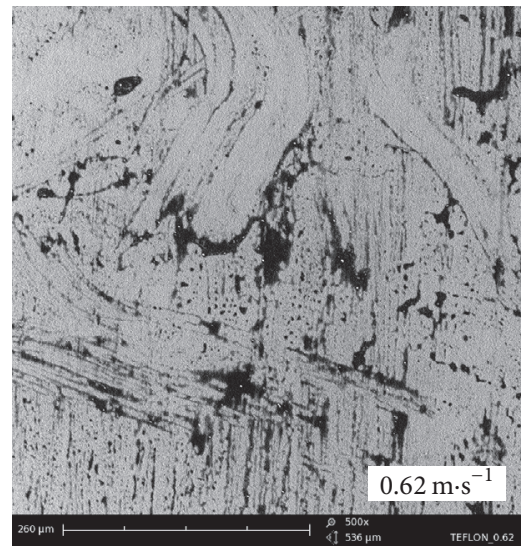

(f)

FIGURE 10: Effect of sliding velocity on worn surfaces of the investigated PTFE: (a) scratches and small discontinuities, (b) plastic deformation, (c) localised worn surface areas, (d) localised worn surface areas and numerous pores, (e) marks of fatigue wear, and (f) localised worn surface areas and numerous pores, SEM.

intensive wear (the largest at $0.26,0.44$, and $0.62 \mathrm{~m} \cdot \mathrm{s}^{-1}$ ), but the wear intensity clearly decreased after exceeding a certain load. A similar regularity was observed for unmodified PP at 0.44 and $0.62 \mathrm{~m} \cdot \mathrm{s}^{-1}$. In general, measurements of linear wear of the tested polymers indicate complexity of their wear process, multitude of factors playing roles in this process, and their variability depending on working conditions, which constitutes a so-far unrecognised research area.

On the grounds of the obtained results, it is possible to verify the accepted and developed models determining changes of friction coefficient in relation to loading force and linear velocity occurring in the friction pair. Till now, several developed models make it possible to foresee behaviour of polymers depending on their grade and load (Shooter and Tabor [23], Bowers et al. [24], Shooter and Thomas [25], Rees [26], and Myshkin et al. [27]). However, on the grounds of analysis of the above-mentioned ascertainments, it is difficult to state clearly which of these models describes behaviours of the polymers used in the own research. Of course, temperature also rises with increasing linear velocity and load and its effect on behaviour of the polymer and change of friction coefficient cannot be omitted $[4,19,28,29]$, so the interactions occurring in the friction pair are quite complex. It was shown in [27] that friction coefficient value is proportional to the loading force. However, the results obtained in own examinations do not confirm this regularity in full: in most variants applied in own research, after a period of increasing with increasing load, stabilisation of friction coefficient was observed. It is only in final range of the test, at significant loads (different for various polymers and working conditions), that destabilisation of the polymer behaviour was found, resulting probably from additional factors occurring in the friction pair, for example, excessive temperature rise in the contact area of mating materials. It should be emphasised that the examinations were carried out till relatively high forces loading the friction pairs, as appeared, in several cases exceeding practical application. So, comprehensive spectrum of evaluation of the examined polymers was obtained, which was an intention of the authors. In should be also mentioned that load can influence temperatures of viscoelastic transitions in polymers and thus their wear mechanism. Viscoelastic behaviour of polymers is also connected with the relation between linear velocity and friction coefficient and, as shown by Brostow et al., [4, 30, 31] 


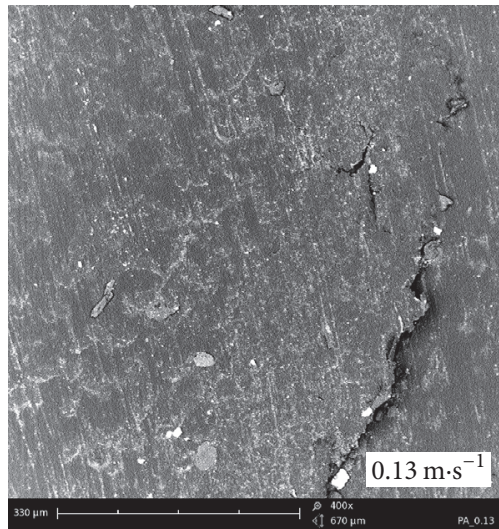

(a)

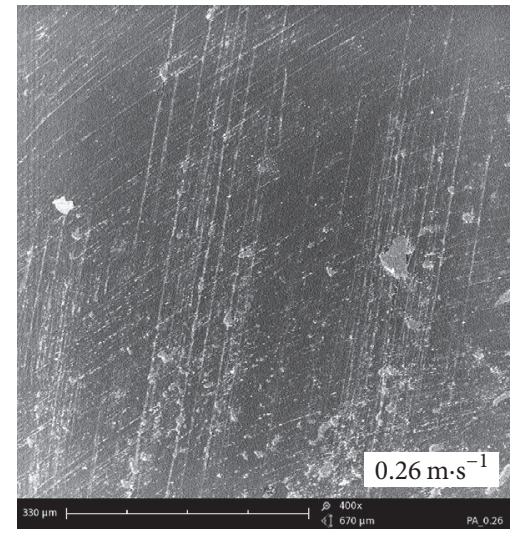

(b)

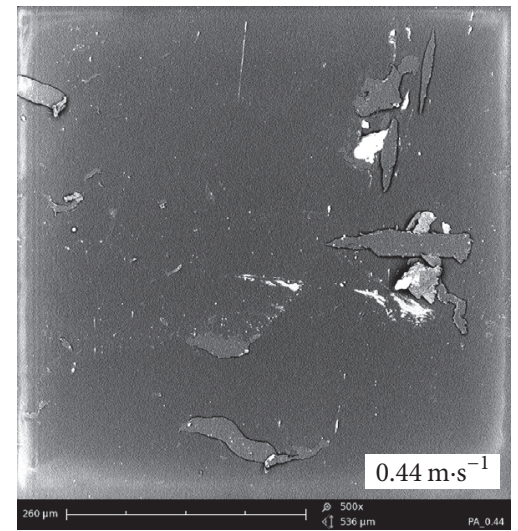

(c)

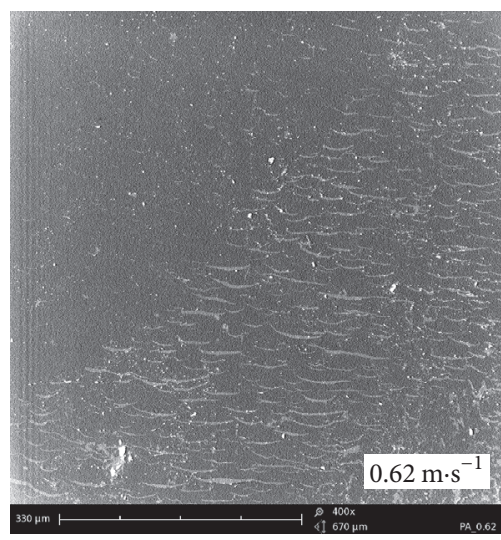

(d)

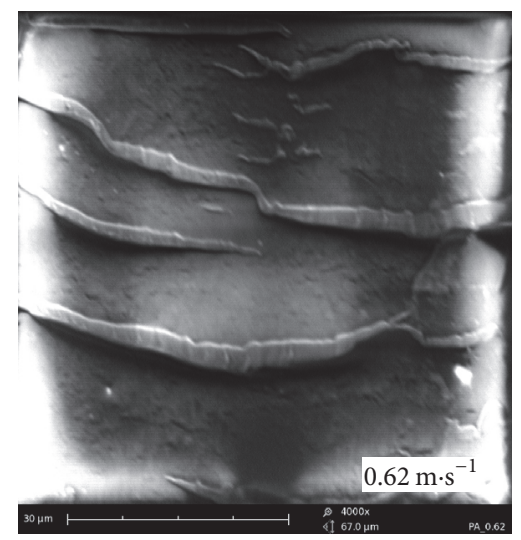

(e)

FIGURE 11: Effect of sliding velocity on worn surfaces of PA 6.6 tested at various sliding velocities: ((a) and (b)) cracks, small parallel scratches, and wear products pressed in the specimen surface, (c) sparse overlaps of the material, (d) zone with scaly structure, formed of "roll-shaped particles," and (e) magnified "roll-shaped particles," SEM.

with brittleness of polymers which is one of the most important criteria determining usable properties of polymers. Such models have been developed by Milz and Sargent [32], Tanaka [33], Flom and Porile [34, 35], and White [36]. When tests are carried out at a temperature close to the glass transition temperature, linear velocity clearly affects friction coefficient but, at lower temperatures, this coefficient depends on linear velocity to a small degree only. Of course, increase of linear velocity itself results in increased temperature of the materials composing the friction pair and such a relationship was noticed in the presented own research.

During the examinations, mechanisms of wear of the examined polymers were determined. Surface analysis of unmodified polypropylene confirmed previous observations described in literature, stating that the main mechanisms of wear in a friction pair polymer-metal are adhesion and surface deformation of soft polymer $[37,38]$. However, when more heat is generated at higher linear velocity and thus temperature on the contact surface rises, the main wear mechanism becomes thermal wear. This type of wear is connected with deformation and next plastic flow of the material, which leads to its significant loss and, in consequence, to catastrophic wear [39]. As a result of thermal wear, value of friction coefficient decreases, so a change of shape of the friction torque curve can be confirmed by observation. Namely, when the polymer melts, its friction coefficient tends to decrease according to the mechanism of "thermal control of friction" [16]. This phenomenon was additionally supported by Quaglini et al. [5]. These authors noticed that when melting temperature of the polymer is reached, generated heat melts additional volume of polymer rather than causing a temperature rise of the already molten material. In accordance with the model of limiting frictional heat which was shown in [16], friction coefficient rises until a maximum value is achieved. At this point, friction coefficient determined by the "thermal control model" equals that dictated by "solid state friction." "Thermal wear" causes the surfaces to be often spreading or even gluing, which leads to catastrophic wear [5]. In the case of unmodified PP, thermal wear takes place at sliding velocity between 0.44 and $0.62 \mathrm{~m} \cdot \mathrm{s}^{-1}$, while in the case of impregnated $\mathrm{PP}$ it takes place at sliding velocity higher than $0.62 \mathrm{~m} \cdot \mathrm{s}^{-1}$. Thus, one of the advantages of impregnation of PP is the possibility of using such modified material under higher loads.

Despite some uncertainties in assessment of wear resistance of the tested PP, it can be considered that the most important finding of this research is that impregnation 


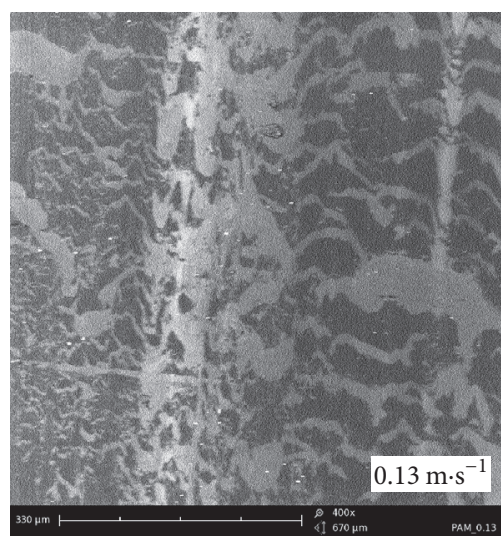

(a)

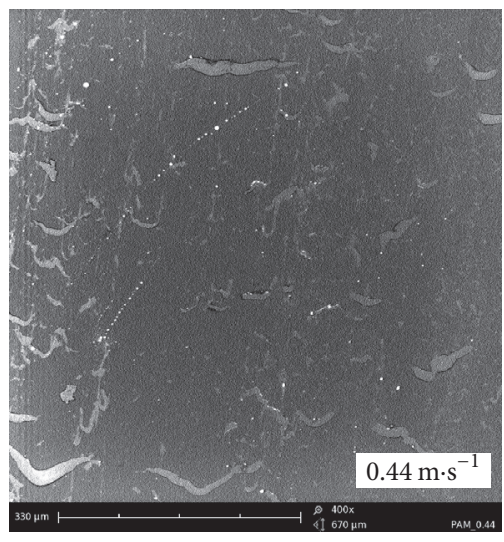

(c)

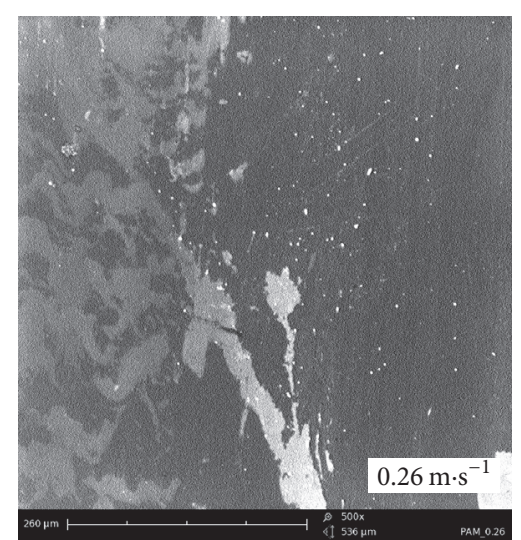

(b)

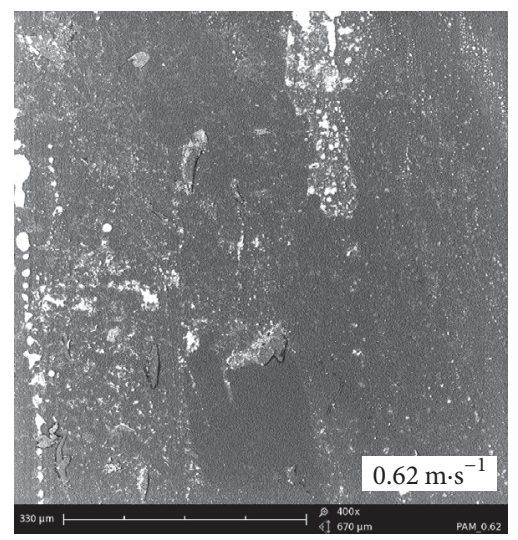

(d)

FIGURE 12: Effect of sliding velocity on worn surfaces of the investigated $\mathrm{PA} \mathrm{MoS}_{2}$ : ((a), (b), and (c)) surface with scale structure, composed of "roll-shaped particles" at various linear velocities, (d) plastic deformations in scaly zone, SEM.

of PP with oil improves its tribological properties at low sliding velocities. Impregnation also moves thermal wear into higher sliding velocities and causes better resistance of PP to melting and plastic flow. According to these results, it can be concluded that impregnation of polypropylene even with inexpensive RME can give some benefits during its use in lowload frictional pairs under dry-friction conditions.

\section{Conclusions}

We conclude the following:

(1) Impregnation of polypropylene with engine oil, gear oil, or RME results in significant reduction of friction coefficient and thus of friction torque in relation to not only unmodified polypropylene but also the examined polyamides and Teflon. It is difficult to indicate the most effective impregnating agent, since different results were found for various working velocities of a friction pair (polymeric specimen and steel counterspecimen), while differences in friction coefficient values for individual impregnating oils were small (till ca. 0.07).

(2) Operation of impregnated polypropylene becomes more stable; that is, polypropylene impregnated with oil is able to work correctly under higher loads and, in particular, at increased sliding velocities.

(3) Within low and medium loads of the friction pair, unmodified polypropylene was characterised by the highest resistance to wear from among the examined polymers. Impregnation with oils resulted in its more intensive wear in comparison to unmodified polypropylene. The smallest differences in intensity of wear occurred in the case of polypropylene impregnated with gear oil and the largest differences-in the case of polypropylene impregnated with RME. Such a regularity took place at lower sliding velocities of the friction pair $\left(0.13\right.$ and $\left.0.26 \mathrm{~m} \cdot \mathrm{s}^{-1}\right)$ and, at low and medium load range, at higher sliding velocities $(0.44$ and $0.62 \mathrm{~m} \cdot \mathrm{s}^{-1}$ ). However, at higher working velocities under high loads, wear of unmodified polypropylene drastically increased, exceeding intensity of wear of impregnated polypropylene.

(4) Intensity of wear of polypropylene impregnated with engine oil and gear oil was slightly lower or comparable to that of other tested polymers (PTFE, PA $\mathrm{MoS}_{2}$, and PA6.6), while Teflon in initial range of load was subjected to intensive wear (the most intensive at 


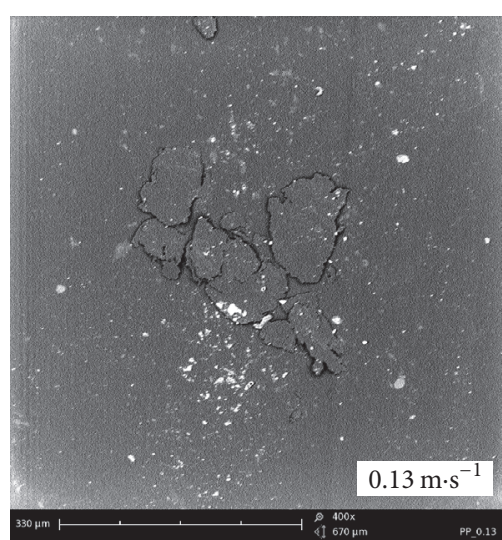

(a)

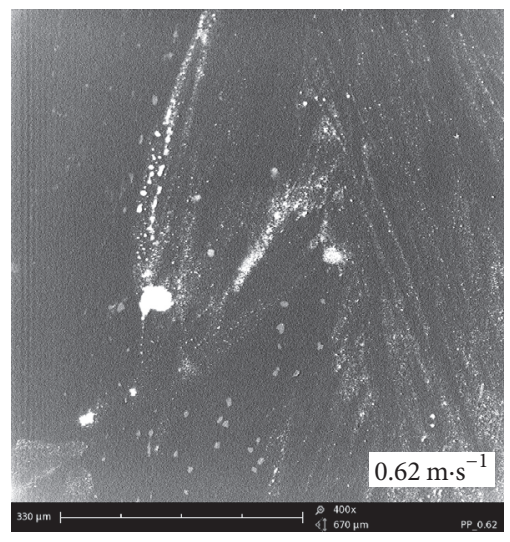

(d)

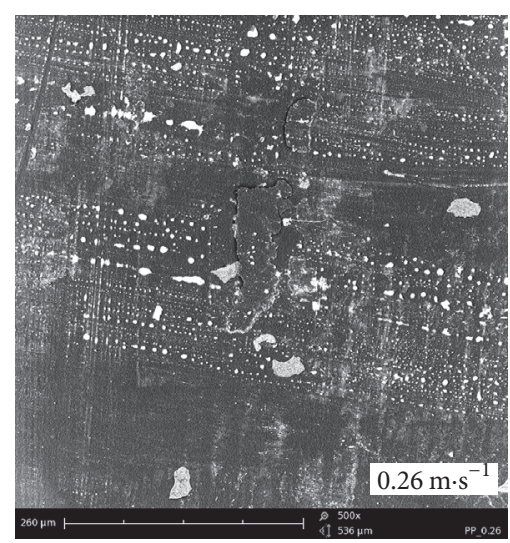

(b)

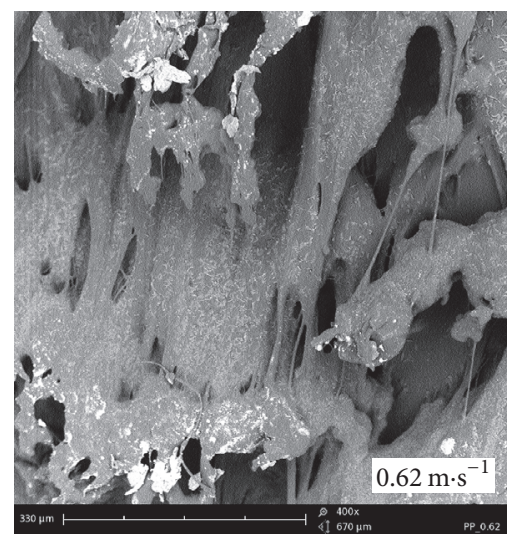

(e)

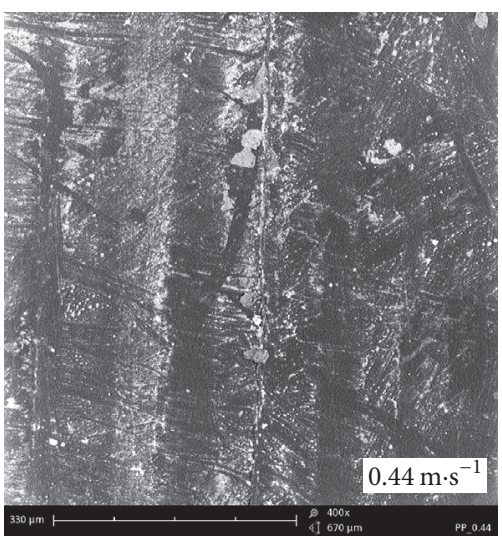

(c)

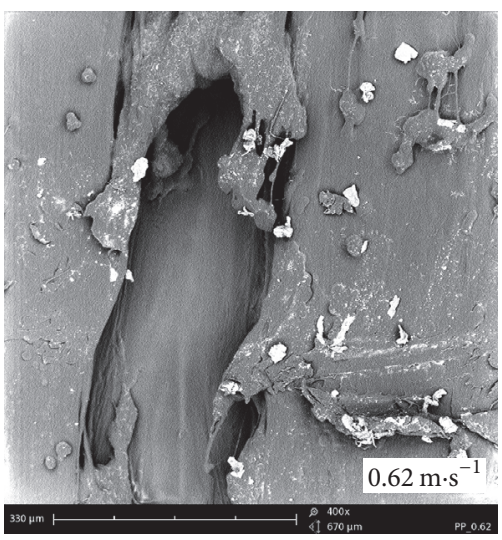

(f)

FIGURE 13: Effect of sliding velocity on worn surfaces of the investigated PA 6.6: ((a) and (b)) shallow scratches and wear traces of adhesive nature; (c) scratches and cracks on the surface; (d) smooth zone with dominating adhesion and microcutting; (e) zone with fracture; bridges with plastically deformed pores between them; (f) zone with fracture, SEM.

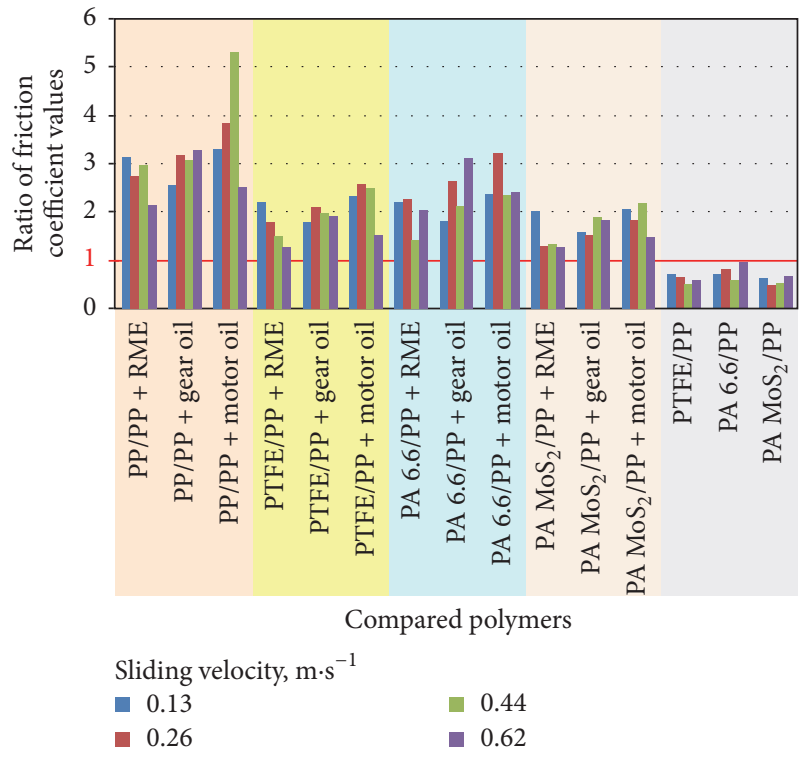

FIGURE 14: Relations between friction coefficient values for the examined polymers depending on sliding velocity.
$0.26,0.44$, and $0.62 \mathrm{~m} \cdot \mathrm{s}^{-1}$ ), and after exceeding some load value its intensity of wear clearly decreased. A similar course of wear curve was found for unmodified polypropylene at sliding velocities of 0.44 and $0.62 \mathrm{~m} \cdot \mathrm{s}^{-1}$.

(5) During the research, mechanisms of wear of unmodified polypropylene, Teflon, and polyamide were identified. The mechanism for polypropylene was complex. At low linear velocity, the main mechanism was adhesive wear. Along with increasing velocity, accompanied by generation of larger amounts of heat, thermal wear started playing a role as the main mechanism of wear. Surface observations made it possible to identify two zones: smooth zone with dominating adhesion and the zone with developed topography including a fracture and plastic deformation.

(6) In the case of the remaining tested polymers, the most important mechanism of wear was adhesion (PTFE, PA 6.6, and PA $\mathrm{MoS}_{2}$ ), microcutting (PTFE, PA 6.6, and PA $\mathrm{MoS}_{2}$ ), fatigue wear (PTFE), and 
formation of "roll-shaped particles" combined with plastic deformation (PA 6.6 and $\mathrm{PA} \mathrm{MoS}_{2}$ ).

\section{Conflicts of Interest}

The authors declare that they have no conflicts of interest.

\section{References}

[1] M. D. Bermudez, W. Brostow, F. J. Carrion-Vilches, and J. Sanes, "Scratch resistance of polycarbonate containing $\mathrm{ZnO}$ nanoparticles: effects of sliding direction," Journal of Nanoscience and Nanotechnology, vol. 10, no. 10, pp. 6683-6690, 2010.

[2] C. J. Hooke, S. N. Kukureka, P. Liao, M. Rao, and Y. K. Chen, "The friction and wear of polymers in non-conformal contacts," Wear, vol. 200, no. 1-2, pp. 83-94, 1996.

[3] D. Rus, L. Capitanu, and L.-L. Badita, "A qualitative correlation between friction coefficient and steel surface wear in linear dry sliding contact to polymers with SGF,' Friction, vol. 2, no. 1, pp. 47-57, 2014.

[4] W. Brostow, V. Kovačević, D. Vrsaljko, and J. Whitworth, "Tribology of polymers and polymer-based composites," Journal of Materials Education, vol. 32, no. 5-6, pp. 273-290, 2010.

[5] V. Quaglini, P. Dubini, D. Ferroni, and C. Poggi, "Influence of counterface roughness on friction properties of engineering plastics for bearing applications," Materials and Corrosion, vol. 30, no. 5, pp. 1650-1658, 2009.

[6] K. Shibata, T. Yamaguchi, and K. Hokkirigawa, "Tribological behavior of polyamide 66/rice bran ceramics and polyamide 66/ glass bead composites," Wear, vol. 317, no. 1-2, pp. 1-7, 2014.

[7] H. Unal, A. Mimaroglu, U. Kadioglu, and H. Ekiz, "Sliding friction and wear behaviour of polytetrafluoroethylene and its composites under dry conditions," Materials and Corrosion, vol. 25, no. 3, pp. 239-245, 2004.

[8] H. Unal and F. Findik, "Friction and wear behaviours of some industrial polyamides against different polymer counterparts under dry conditions," Industrial Lubrication and Tribology, vol. 60, no. 4, pp. 195-200, 2008.

[9] B. S. Ünlü, E. Atik, and S. S. Yilmaz, “Tribological behaviors of polymer based journal bearings manufactured from particle reinforced bakelite composites," Materials and Corrosion, vol. 30, no. 9, pp. 3896-3899, 2009.

[10] V. K. Thakur and A. S. Singha, "Physico-chemical and mechanical characterization of natural fibre reinforced polymer composites," Iranian Polymer Journal, vol. 19, no. 1, pp. 3-16, 2010.

[11] B.-B. Jia, T.-S. Li, X.-J. Liu, and P.-H. Cong, "Tribological behaviors of several polymer-polymer sliding combinations under dry friction and oil-lubricated conditions," Wear, vol. 262, no. 11-12, pp. 1353-1359, 2007.

[12] P. Sędłak, B. Białobrzeska, and T. Stawicki, "Friction coefficient and wear resistance of a modified polypropylene impregnated with different oils," Iranian Polymer Journal, vol. 25, no. 3, pp. 263-275, 2016.

[13] Z. Lawrowski, "Polymers in the construction of serviceless sliding bearings," Archives of Civil and Mechanical Engineering, vol. 7, no. 4, pp. 139-150, 2007.

[14] Z. Rymuza, “Tribology of polymers," Archives of Civil and Mechanical Engineering, vol. 7, no. 4, pp. 177-184, 2007.

[15] K. R. Makinson and D. Tabor, "Friction and transfer of polytetrafluoroethylene," Nature, vol. 201, no. 4918, pp. 464-466, 1964.
[16] C. M. M. Ettles, "Polymer and elastomer friction in the thermal control regime," Tribology Transactions, vol. 30, no. 2, pp. 149$159,1987$.

[17] N. E. Bekhet and S. A. Naga, "An assessment of the frictional and wear behaviour of polyethylener steel couple," in Proceedings of the EGTRIB-92, the 3rd Conference of the Egyptian Society of Tribology, pp. 41-53, 1992.

[18] M. D. Bermudez, W. Brostow, F. J. Carrion-Vilches, J. J. Cervantes, G. Damarla, and J. M. Perez, "Scratch velocity and wear resistance," e-Polymers, vol. 3, pp. 1-10, 2005.

[19] W. Brostow, J.-L. Deborde, M. Jaklewicz, and P. Olszynski, “Tribology with emphasis on polymers: friction, scratch resistance and wear," Journal of Materials Education, vol. 25, no. 4-6, pp. 119-132, 2003.

[20] T. Cousseau, B. M. Graça, A. V. Campos, and J. H. O. Seabra, "Influence of grease rheology on thrust ball bearings friction torque," Tribology International, vol. 46, pp. 106-113, 2012.

[21] I. Couronné, P. Vergne, D. Mazuyer, N. Truong-Dinh, and D. Girodin, "Effects of grease composition and structure on film thickness in rolling contact," Tribology Transactions, vol. 46, no. 1, pp. 31-36, 2003.

[22] T. Cousseau, B. Graça, A. Campos, and J. Seabra, "Friction torque in grease lubricated thrust ball bearings," Tribology International, vol. 44, no. 5, pp. 523-531, 2011.

[23] K. V. Shooter and D. Tabor, "The frictional properties of plastics," Proceedings of the Physical Society, Section B, vol. 65, no. 9, pp. 661-671, 1952.

[24] R. C. Bowers, W. C. Clinton, and W. A. Zisman, "Frictional behavior of polyethylene, polytetrafluorethylene and halogenated derivatives," Lubrication Engineering, vol. 9, pp. 204209, 1953.

[25] K. Shooter and R. H. Thomas, "Frictional properties of some plastics," Research, vol. 2, pp. 533-539, 1952.

[26] B. L. Rees, "Static friction of bulk polymers over a temperature range," Research, vol. 10, pp. 331-338, 1957.

[27] N. K. Myshkin, M. I. Petrokovets, and A. V. Kovalev, "Tribology of polymers: adhesion, friction, wear, and mass-transfer," Tribology International, vol. 38, no. 11-12, pp. 910-921, 2005.

[28] G. V. Vinogradov, G. M. Bartenev, A. I. El'kin, and V. K. Mikhaylov, "Effect of temperature on friction and adhesion of crystalline polymers," Wear, vol. 16, no. 3, pp. 213-219, 1970.

[29] W. Brostow and H. E. H. Lobland, Materials: Introduction and Applications, John Wiley \& Sons, New York, NY, USA, 2017.

[30] W. Brostow, H. E. Hagg Lobland, and M. Narkis, "Sliding wear, viscoelasticity, and brittleness of polymers," Journal of Materials Research, vol. 21, no. 9, pp. 2422-2428, 2006.

[31] W. Brostow and H. E. H. Lobland, "Survey of relations of chemical constituents in polymer-based materials with brittleness and its associated properties," Chemistry \& Chemical Technology, vol. 10, no. 4, pp. 595-560, 2016.

[32] W. C. Milz and L. E. Sargent, "Frictional characteristic of plastics," Lubrication Engineering, vol. 11, pp. 313-317, 1955.

[33] K. Tanaka, "Kinetic friction and dynamic elastic contact behaviour of polymers," Wear, vol. 100, no. 1-3, pp. 243-262, 1984.

[34] D. G. Flom and N. T. Porile, "Effects of temperature and highspeed sliding on the friction of 'teflon' on 'teflon," Nature, vol. 175, pp. 682-685, 1955.

[35] D. G. Flom and N. T. Porile, "Friction of Teflon sliding on Teflon," Journal of Applied Physics, vol. 26, no. 9, pp. 1088-1092, 1955. 
[36] H. S. White, "Small oil-free bearings," Journal of Research of the National Bureau of Standards, vol. 57, no. 4, pp. 185-189, 1956.

[37] N. E. Bekhet, "Tribological behaviour of drawn polypropylene," Wear, vol. 236, no. 1-2, pp. 55-61, 1999.

[38] S. Bahadur and K. C. Ludema, "The viscoelastic nature of the sliding friction of polyethylene, polypropylene and copolymers," Wear, vol. 18, no. 2, pp. 109-128, 1971.

[39] W. Wieleba, "The mechanism of tribological wear of thermoplastic materials," Archives of Civil and Mechanical Engineering, vol. 7, no. 4, pp. 185-199, 2007. 

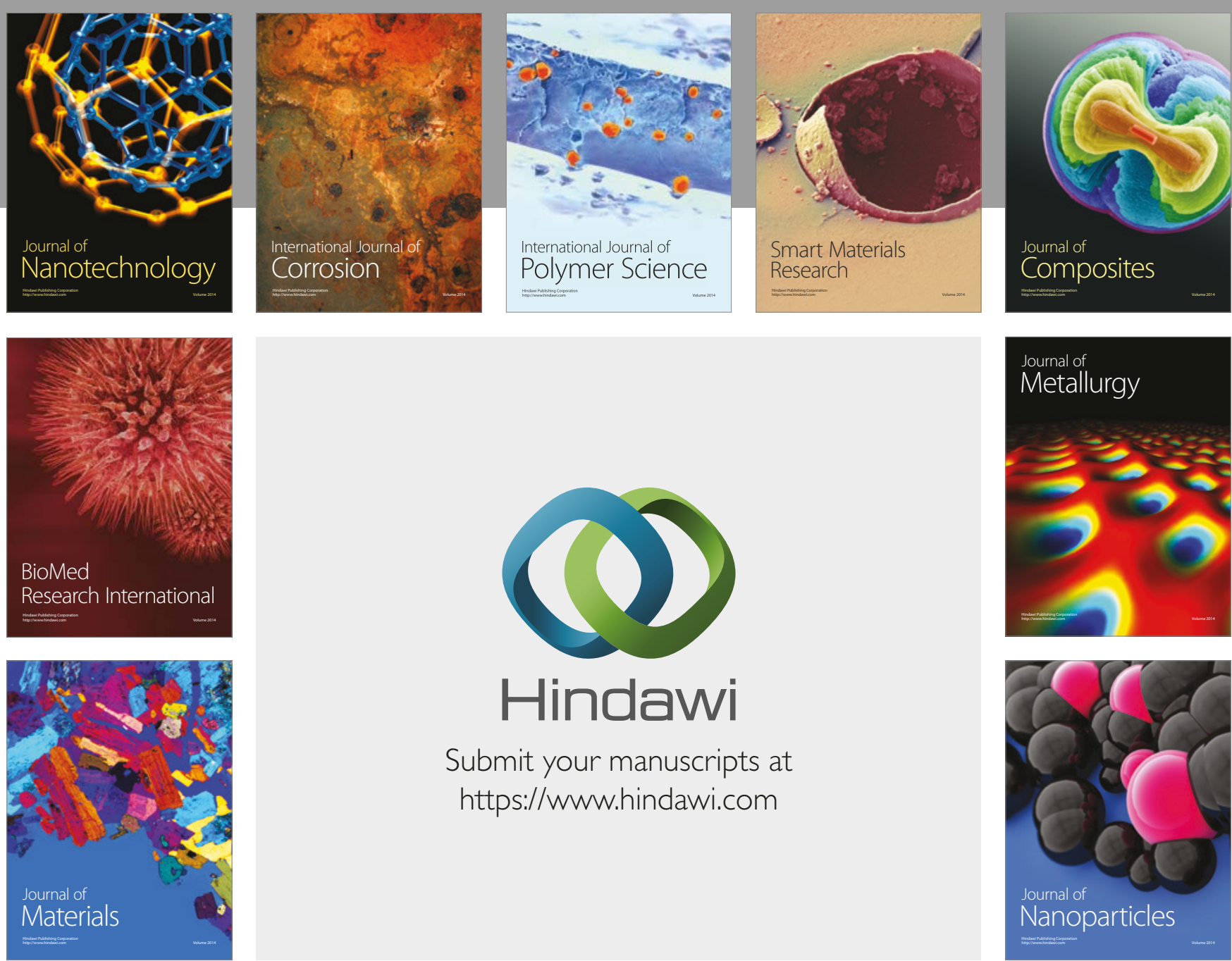

\section{Hindawi}

Submit your manuscripts at

https://www.hindawi.com
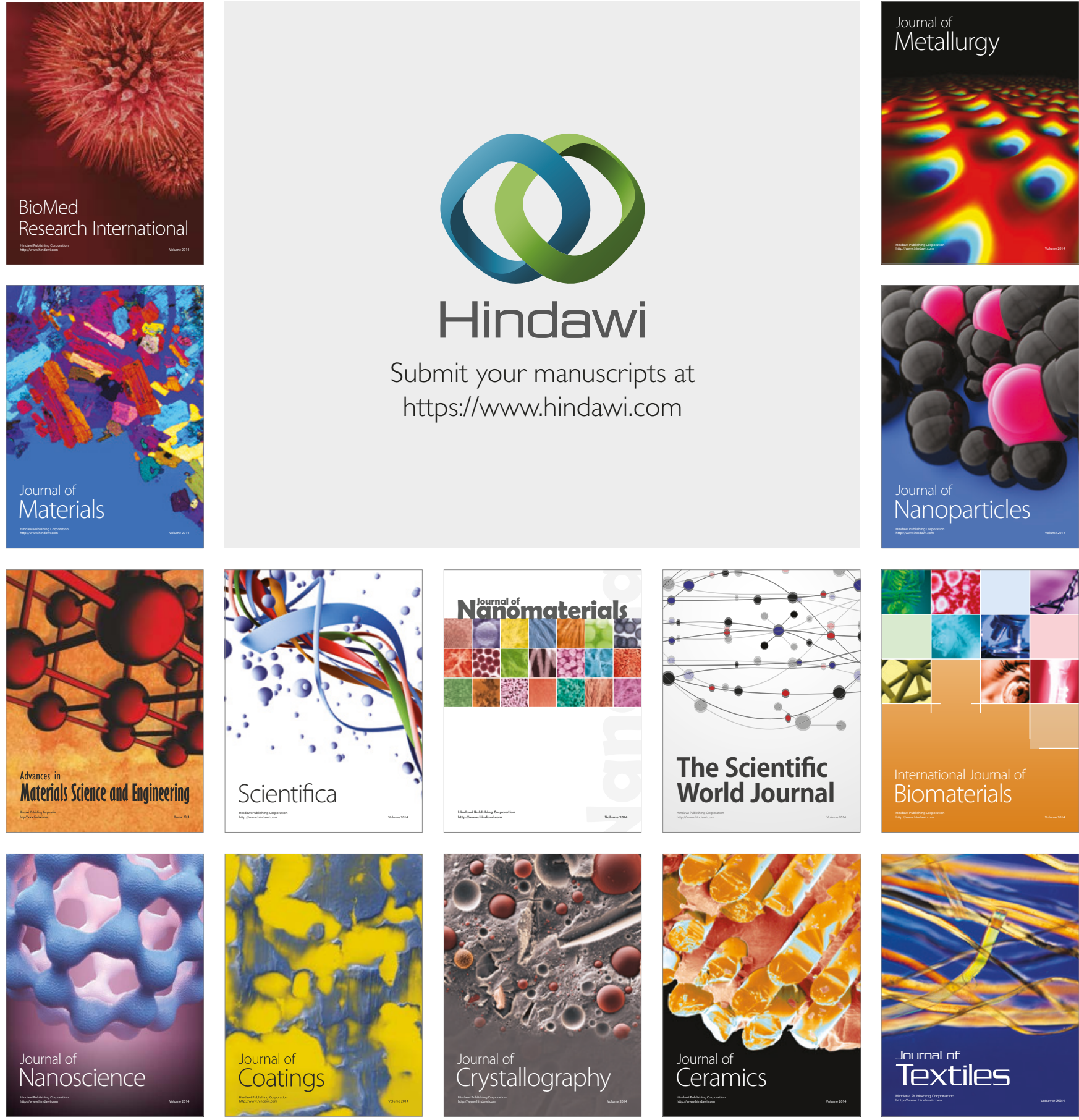

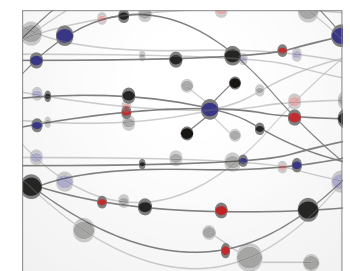

The Scientific World Journal
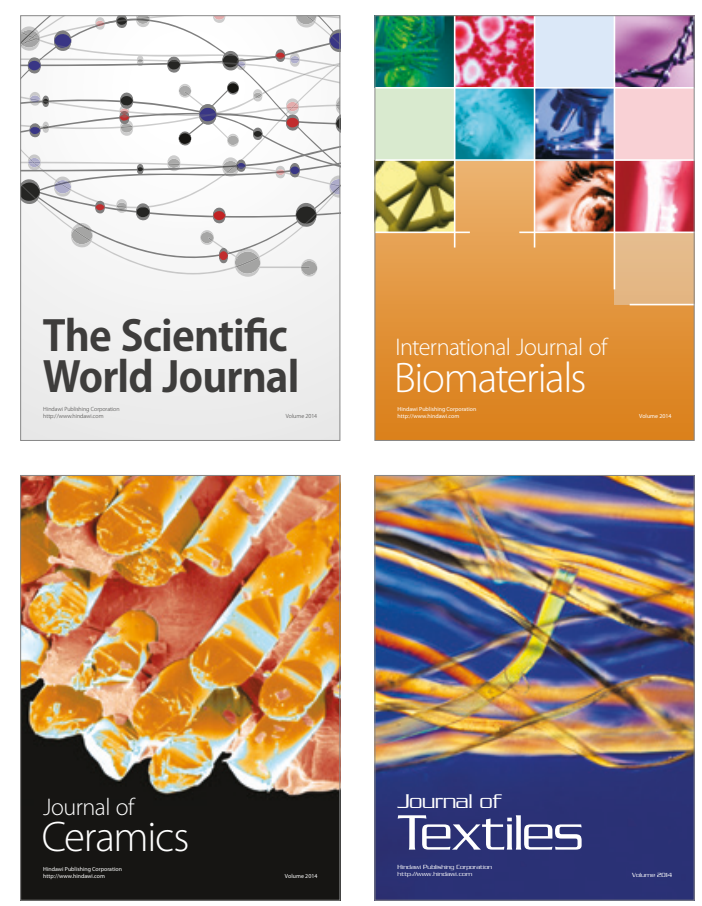